\title{
Boosting for concept design of casting aluminum alloys driven by combining computational thermodynamics and machine learning techniques
}

\author{
Wang Yi', Guangchen Liu',2, Jianbao Gao', Lijun Zhang ${ }^{1}$ \\ 'State Key Laboratory of Powder Metallurgy, Central South University, Changsha 410083, Hunan, China. \\ ${ }^{2}$ Mechanical Engineering Department, Worcester Polytechnic Institute, Worcester, MA 01609, USA. \\ *Correspondence to: Dr. Jianbao Gao, State Key Laboratory of Powder Metallurgy, Central South University, Changsha \\ 410083, Hunan, China. E-mail: jianbao.gao@csu.edu.cn; Prof. Lijun Zhang, State Key Laboratory of Powder Metallurgy, Central \\ South University, Changsha 410083, Hunan, China. E-mail: lijun.zhang@csu.edu.cn
}

How to cite this article: Yi W, Liu G, Gao J, Zhang L. Boosting for concept design of casting aluminum alloys driven by combining computational thermodynamics and machine learning techniques. J Mater Inf 2021;1:11. https://dx.doi.org/10.20517/jmi.2021.10

Received: 1 Nov 2021 First Decision: 8 Dec 2021 Revised: 20 Dec 2021 Accepted: 27 Dec 2021 Published: 30 Dec 2021

Academic Editor: Xingjun Liu Copy Editor: Xi-Jun Chen Production Editor: Xi-Jun Chen

\begin{abstract}
Casting aluminum alloys are commonly used in industries due to their excellent comprehensive performance. Alloying/microalloying and post-solidification heat treatments are the most common measures to tune the microstructure for enhancing their mechanical properties. However, it is very challenging to achieve accurate and efficient development of novel casting aluminum alloys using the traditional trial-and-error method. With the rapid development of computer technology, the computational thermodynamics (CT) in the framework of the CALculation of PHAse Diagram approach, the data-driven machine learning (ML) technique, and also their combinations have been proved to be effective approaches for the design of casting aluminum alloys. In this review, the state-of-the-art computational alloy design approaches driven by $C T$ and $M L$ techniques, as well as their combinations, were comprehensively summarized. The current status of the thermodynamic database for aluminum alloys, as the core for $\mathrm{CT}$, was also briefly introduced. After that, a variety of successful case studies on the design of different casting aluminum alloys driven by $C T, M L$, and their combinations were demonstrated, including common applications, CT-driven design of Sc-additional Al-Si-Mg series casting alloys, and design of Srmodified A356 alloys driven by combing CT and ML. Finally, the conclusions of this review were drawn, and perspectives for boosting the computational design approach driven by combining $\mathrm{CT}$ and $\mathrm{ML}$ techniques were pointed out.
\end{abstract}

Keywords: Casting aluminum alloy, alloy design, computational thermodynamics, machine learning 


\section{INTRODUCTION}

Nowadays, more than several dozens of aluminum alloys are utilized in the aerospace, automotive, electronics, and building industries because of their advantages such as high strength-to-weight ratio, superior castability, low thermal expansion coefficient, and outstanding corrosion resistance ${ }^{[1-3]}$. With the advantages in low cost, high productivity, and high compatibility with recycling processes, casting is the most flexible method for fabricating complex shapes, and approximately $30 \%$ of the total aluminum products and most of the special-shaped pieces are manufactured in this way ${ }^{[4]}$. In most cases, only four alloying elements are used in cast aluminum alloys: semiconductor silicon; and metals magnesium, zinc, and copper ${ }^{[5]}$. These chemical elements are referred to as "basic" or "principal" because they are present in relatively large amounts in aluminum alloys and determine their microstructure and properties. Therefore, according to the difference in alloying elements, casting aluminum alloys are mainly divided into four categories: Al-Si system, Al-Mg system, Al-Cu system, and Al-Zn system, as summarized in Figure 1. As shown in the figure, aluminum-silicon alloys with high specific strength, low density, and low thermal expansion coefficient are widely used as materials for cylinder heads, engine blocks, and wheels ${ }^{[6-8]} . \mathrm{Al}-\mathrm{Mg}$ alloys are widely applied in radar bases, aircraft landing gear, marine, and food and beverage packaging due to their corrosion resistance, appreciable mechanical properties, low density, and formability ${ }^{[9-12]}$. Al-Cu alloys have applications in structural, aerospace, marine, and automotive industries for their high strength $^{[13,14]}$. Due to the high strength obtained by fine-scale precipitation of the metastable zinc-rich phase in the hardening heat treatment process, $\mathrm{Al}-\mathrm{Zn}$ alloys are widely used in aircraft manufacturing and other high-strength applications ${ }^{[15-17]}$.

However, the mechanical properties of original casting aluminum alloys are still lower than those of wrought aluminum alloys ${ }^{[18-20]}$. For instance, the microstructural problem of Al-Si alloys induced by the formation of a flake-type brittle ( $\mathrm{Si}$ ) phase during solidification, the low toughness of $\mathrm{Al}-\mathrm{Cu}$ alloys, the low ductility of Al-Mg alloys, and the intergranular and stress corrosion cracking of Al- $\mathrm{Zn}$ alloys restrict the application of casting aluminum alloys. Therefore, to expand the application range of casting aluminum alloys, it is necessary to further improve the properties/performance of the casting aluminum alloys. The mechanical properties of aluminum castings may be modified through tuning the casting process, alloying composition, and heat treatment ${ }^{[20]}$. Aluminum alloys can basically be cast by all the existing processes, such as pressure die casting, plaster molds, permanent mold, clay/water bonded sand, chemically bonded sand, and investment casting. Important developments include rapid solidification ${ }^{[21]}$, high-pressure solidification $^{[22]}$, high-pressure die casting ${ }^{[23]}$, and additive manufacturing ${ }^{[24]}$, as well as technologies of compensating for solidification-related microstructural and macrostructural tendencies ${ }^{[25,26]}$. However, each casting technology defines a series of limits and requires adaptations of the alloys and adjustments to the post-solidification heat treatment. Meanwhile, alloying/microalloying has become the most promising strategy for further modification of the microstructure and improvement of the mechanical properties of casting $\mathrm{Al}$ alloys. With extensive efforts for the past half-century, a variety of grain refiners and modifiers (i.e., $\mathrm{Na}^{[27]}, \mathrm{Sr}^{[28]}, \mathrm{Ti}^{[29]}, \mathrm{B}^{[30]}, \mathrm{V}^{[31]}, \mathrm{Nb}^{[32]}, \mathrm{Zr}^{[33]}, \mathrm{Ce}^{[34]}, \mathrm{P}^{[35]}$ and $\mathrm{Sc}^{[36]}$ ) have been proposed to ameliorate the mechanical properties of casting aluminum alloys. What's more, the post-heat treatment of casting aluminum alloys is typically based on the adjustment of the solubilities of the metallurgical phase in a crystallographically monotropic system, and the mechanical properties of cast aluminum alloys can be manipulated by controlling the formation and content of precipitated phases ${ }^{[37,38]}$. 


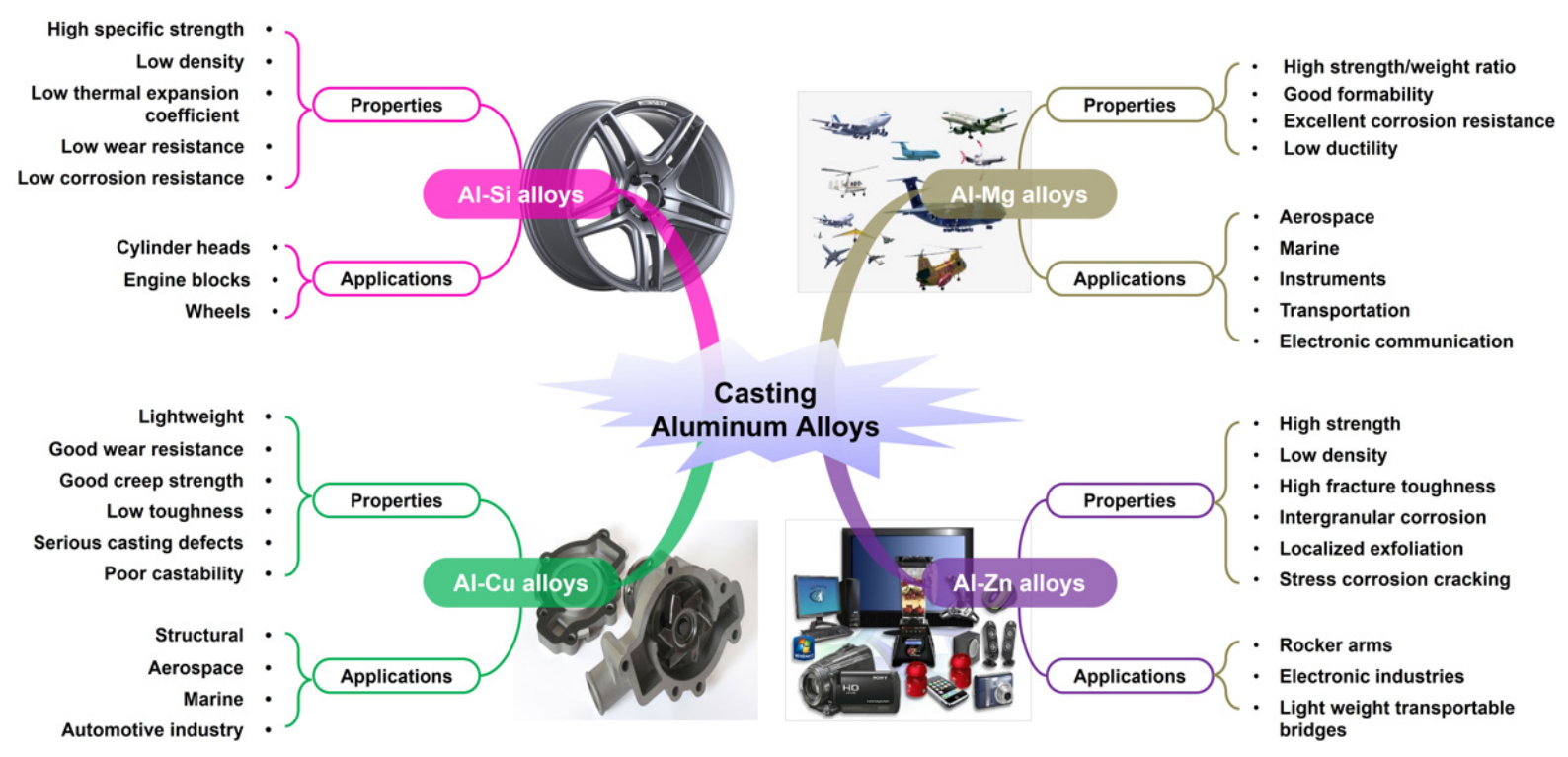

Figure 1. Classification system for casting aluminum alloys.

Traditional trial-and-error method is widely used to search for the optimal alloy composition and heat treatment mechanism for casting aluminum alloys with the best mechanical properties; however, it is timeconsuming and challenging to accurately and efficiently design the optimal alloy composition and heat treatment mechanisms, especially in multicomponent aluminum alloys. In this context, with the development of computer technology, computational alloy design approaches based on theoretical modeling/prediction can effectively accelerate the design of alloy compositions, heat treatment mechanisms, and even manufacturing processes. In fact, this is also the ultimate goal in the field of materials science. To date, many approaches are available for theoretical alloy design, such as first-principles (FP) calculations ${ }^{[39]}$, molecular dynamics simulations ${ }^{[40]}$, computational thermodynamics $(\mathrm{CT})^{[41-43]}$, computational kinetics ${ }^{[4-51]}$ in the framework of CALculation of PHAse Diagram (CALPHAD) technique, phase-field simulations ${ }^{[52-56]}$, machine learning (ML) approach ${ }^{[57-60]}$, and other empirical/semi-empirical formulas ${ }^{[61-63]}$. Among them, CT in the framework of CALPHAD technique and data-driven ML method is the most advantageous approach for multicomponent alloy design. The CT approach, of which the greatest advantage lies in an efficient and accurate guide about the equilibrium/nonequilibrium phase relations, has been used for material design and process optimization of commercial multicomponent aluminum alloys for more than twenty years ${ }^{[6,65]}$. In recent years, the CALPHAD method has been widely applied in the calculation of the phase equilibria and thermodynamic properties in aluminum alloys. However, it is impossible to construct the quantitative relation between the microstructure and mechanical properties with only the CT approach. The data-driven ML method, whose most significant advantage lies in that the relation between any two types of variables without knowing their physical connection in advance can be effectively established, has been successfully applied in the computer science community ${ }^{[6]}$. Recently, it has aroused great interest in the materials industry in crack location prediction, structure analysis ${ }^{[67]}$, physical property prediction ${ }^{[68]}$, and alloy design ${ }^{[69]}$. However, with the relations trained by ML method, it is challenging to understand the physical context in the target alloys. Moreover, accurate ML predictions also strongly depend on a large dataset of the target alloys. Therefore, a combination of the CT method and ML method has been naturally proposed, with which the CT approach is used to build the quantitative relation of "Composition - Process Microstructure", and the data-driven machine learning is utilized to construct the quantitative relation of "Microstructure - Properties". Such a combination is expected to boost the efficient and accurate design of multicomponent casting aluminum alloys. 
Consequently, the aim of this review is forced on a comprehensive summary of all the efforts in the computational alloy design of different casting aluminum alloys using the CT approach, ML techniques, and their combinations, and to provide a clear vision for boosting the concept design of casting aluminum alloys. In the next section, the state-of-the-art alloy design approaches driven by CT, ML, and their combinations will be reviewed. The current status and development of the thermodynamic databases for aluminum alloys are briefly introduced. After that, some successful case studies on the computational design of casting aluminum alloys driven by CT, ML, and their combinations are presented. Finally, the conclusions will be drawn, and some promising prospects for broadening the application range of the computational alloy design approach driven by a combination of CT and ML in casting aluminum alloys are also pointed out.

\section{STATE-OF-THE-ART OF COMPUTATIONAL ALLOY DESIGN APPROACHES: COMPUTATIONAL THERMODYNAMICS, MACHINE LEARNING, AND THEIR COMBINATIONS}

\section{Computational thermodynamics technique and its applications}

A detailed understanding of the stability relation of the aluminum alloy system is helpful to the design of aluminum alloys for specific applications ${ }^{[70]}$. Olson ${ }^{[71]}$, Olson and Kuehmann ${ }^{[72]}$ pointed out that the conceptual design of structured material can be achieved through a systematic approach that integrates manufacturing, structure, property, and performance relations through a hierarchical computational model, and defines subsystem design parameters through the CT technique. Based on the CALPHAD method dawned in the 1950s, the CT technique aimed at the coupling of phase equilibrium and thermochemistry by computational techniques, and eventually evolved into kinetics simulations with thermodynamic calculations, becoming a powerful tool for material design ${ }^{[73-75]}$. The multicomponent phase equilibria can be calculated, and the solidification process of multicomponent alloys of industrial relevance can be simulated once a thermodynamic database has been developed for the target multicomponent system ${ }^{[76-80]}$. The strategic workflow for the alloy design approach driven by computational thermodynamics is shown in Figure 2. As demonstrated in the figure, computational thermodynamics based on a reliable thermodynamic database and software/code can provide accurate predictions of different factors determining the castability ${ }^{[81-86]}$, cracking tendency ${ }^{[87-90]}$, grain refinement ${ }^{[91-93]}$, microstructure modification ${ }^{[94-97]}$, and basic physical properties ${ }^{[98-101]}$ of casting aluminum alloys, from which the alloy composition ${ }^{[95]}$, heat treatment mechanism $s^{[102]}$ and even manufacturing means ${ }^{[102]}$ can be optimized, e.g., by using multi-objective design strategy.

\section{Castability of aluminum alloys}

It is well known that not all elemental interactions are beneficial to the improvement of alloy properties. Alloying elements can either cooperate or compete with each other in phase equilibrium ${ }^{[83]}$. The formation of unnecessary and even harmful phases commonly occurs in a multicomponent aluminum alloy system without scientific guidance. This leads directly to the most common negative effect of alloying element interactions: the waste of solute elements in an unwanted phase. In this way, not only the alloying effect is weakened, but also the harmful phases can directly weaken the properties of the alloy. In this context, to study the castability of aluminum alloy, it should be the first step to understand the phase equilibrium information of multicomponent aluminum alloy systems. Schmid-Fetzer and Zhang ${ }^{[82]}$ systematically studied the influence of trace elements (i.e., $\mathrm{Cr}, \mathrm{Fe}, \mathrm{Mn}, \mathrm{Si}$, and $\mathrm{Ti}$ ) on the liquidus and solidus temperatures of $\mathrm{Al}-2.3 \mathrm{Cu}-2.25 \mathrm{Mg}-6.2 \mathrm{Zn}-0.115 \mathrm{Zr}$ (in wt\%) alloy. The liquidus and solidus of fcc phase were calculated to be $630.8{ }^{\circ} \mathrm{C}$ and $496{ }^{\circ} \mathrm{C}$, respectively. High-throughput calculations (HTCs) were also performed on the alloys with the addition of minor alloying elements in their specified ranges of $\mathrm{Al}-2.3 \mathrm{Cu}-2.25 \mathrm{Mg}-6.2 \mathrm{Zn}$ $0.115 \mathrm{Zr}-(0 \sim 0.04) \mathrm{Cr}-(0 \sim 0.15) \mathrm{Fe}-(0 \sim 0.1) \mathrm{Mn}-(0 \sim 0.12) \mathrm{Si}-(0 \sim 0.06) \mathrm{Ti}$ (in wt\%). The calculated liquidus 


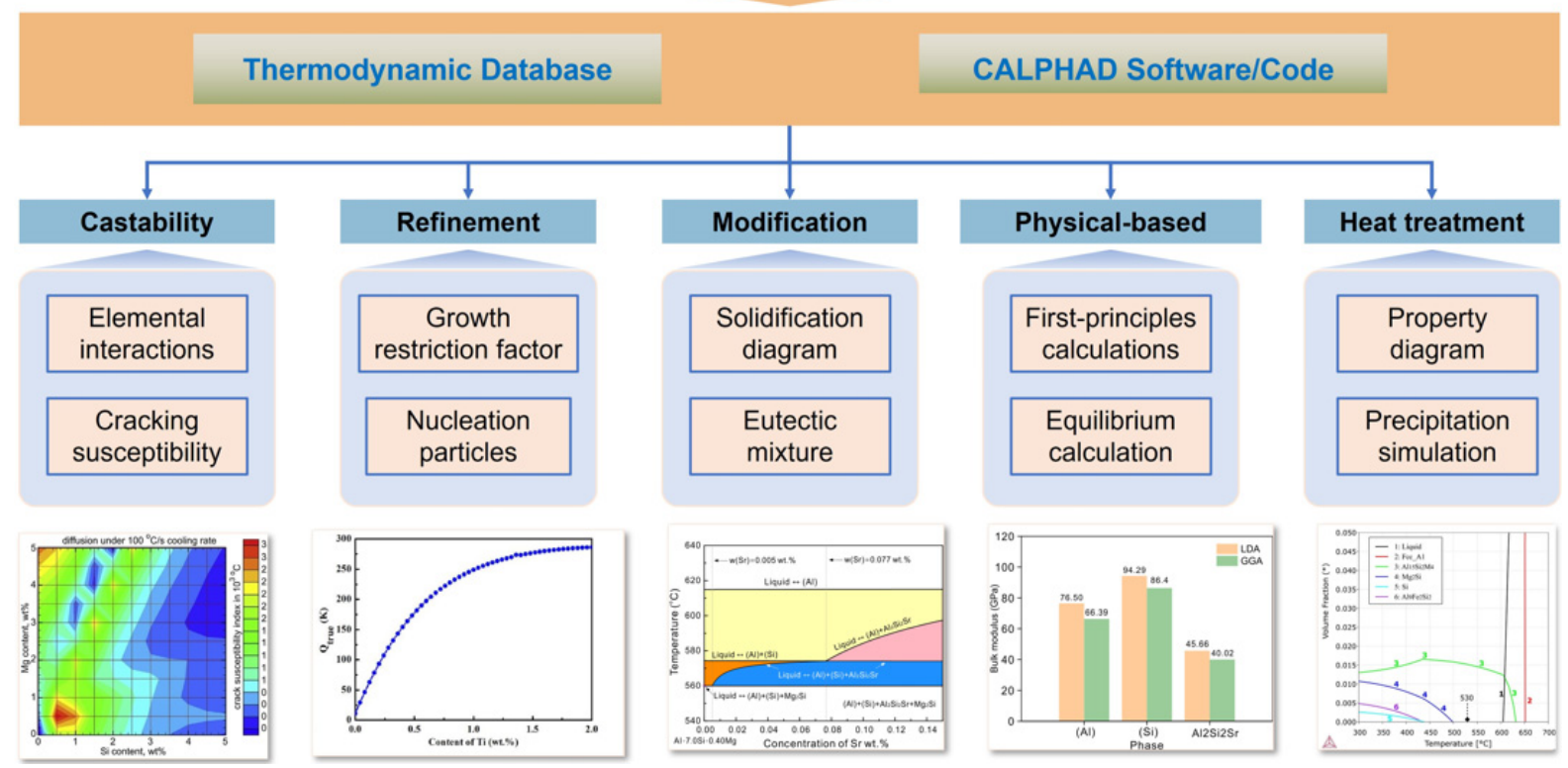

Figure 2. Strategic workflow for alloy design approach driven by computational thermodynamics.

temperatures are in the range of $629-633^{\circ} \mathrm{C}$, while the calculated solidus temperatures distribute in the range of $488-508{ }^{\circ} \mathrm{C}$. The influence of trace elements on the liquidus of the alloys was insignificant, i.e., $\sim \pm 2{ }^{\circ} \mathrm{C}$, while the influence on the solidus was more significant, $\sim \pm 10^{\circ} \mathrm{C}$. Although the percentages of minor elements are very low, their effect cannot be simply ignored, and thus understanding the effect of minor elements is important. Moreover, for Al-Si alloys, the addition of Si can greatly increase the fluidity of the melt and improve castability. However, with the addition of other major or minor elements, the elemental interactions often occur, which leads to the poisoning of $\mathrm{Si}^{[30-32]}$, decreasing the castability of alloys. Therefore, to improve the castability of aluminum alloy, it is necessary to strictly control the amount of alloying elements.

Alloy solidification is usually accompanied by volume changes, which may cause porosity, shrinkage, and other casting defects in the casting parts. A small volume shrinkage is usually considered as an increase in the castability of the alloy. For instance, it is widely accepted that a high level of additional Si into casting aluminum alloys contributes to good casting characteristics. That is partly because the additional Si can reduce the volume shrinkage according to the density calculation by Chen et al. ${ }^{[65]}$. With the increase of Si content, the melt density increases while the solid density decreases, thus reducing the casting shrinkage. Beyond the densities, the castability of the alloy is also affected by the viscosity/diffusivity ${ }^{[103]}$, degree of undercooling ${ }^{[52]}$, cooling rate ${ }^{[84,85]}$, and CCT/TTT diagrams ${ }^{[86]}$, which can be accurately analyzed by combing thermodynamic calculations and kinetic simulations. A typical demonstration is from Tang et al. ${ }^{[81]}$, who achieved the quantitative simulation of microstructure evolution during the solidification and dissolution process based on the composition- and temperature-dependent viscosities and diffusivities of the liquid and fcc phases in ternary Al-Mg-Si system.

Furthermore, the cracking during solidification also significantly affects the castability of aluminum alloy. Solidification cracking in aluminum alloys is a serious defect, which will further affect their mechanical properties and then comprehensive performance. As derived by Kou ${ }^{[87,88]}$, Soysal and $\mathrm{Kou}^{[00]}$, Liu and 
$\mathrm{Kou}^{[104]}$, the index of $\left|\mathrm{d} T / \mathrm{d}\left(f_{s}\right)^{1 / 2}\right|$ near $\left(f_{s}\right)^{1 / 2}=1$ can be used as one of the effective criteria for the cracking susceptibility of aluminum alloys, where $T$ is the solidification temperature and $f_{s}$ is the solid fraction, and $T$ and $f_{s}$ can be acquired by the Scheil-Gulliver solidification simulations. The higher values of $\left|\mathrm{d} T / \mathrm{d}\left(f_{s}\right)^{1 / 2}\right|$ suggest the low lateral growth rate for columnar grains at the end of solidification, where the columnar grains are easily separated by the thin liquid films, and the alloy exhibits greater crack tendency, which leads to lower strength and ductility of the target alloy. The criterion proposed by Liu and $\mathrm{Kou}^{[89]}$, Zhang et al. ${ }^{[105]}$, Kou et al. ${ }^{[106]}$, Liu et al. ${ }^{[107]}$ has been successfully applied to predict crack susceptibility of the industrial aluminum alloys.

\section{Grain refinement}

It is an efficient way to improve the mechanical properties of aluminum alloys by refining the grain size of the phases forming during casting. The nucleation rate and the growth rate of crystals are known to be the two key factors that determine the final microstructure of the target alloy. Through alloying/microalloying, the strong nucleation particles (i.e., $\mathrm{Al}_{3} \mathrm{Ti}^{[30]}, \mathrm{TiB}_{2}{ }^{[108]}, \mathrm{AlB}_{2}{ }^{[109]}, \mathrm{Al}_{3} \mathrm{Nb}^{[110]}$ ) formed in cast aluminum alloy can produce the microstructures with fine equiaxed grains, which can improve the mechanical properties of the aluminum casting. The thermodynamic calculations and Scheil-Gulliver simulations in the framework of the CALPHAD method are usually employed to clarify the types and form conditions of the nucleating particles in alloys. Moreover, when the solute diffusion in liquid is rate-controlling, the presence of solutes leads to growth restriction. The growth restriction factor ( $Q$-value) has frequently been used to analyze and control grain refinement during the solidification of aluminum alloys ${ }^{[91-93]}$. It has been demonstrated that the Q-value in multicomponent alloys can be predicted from nonequilibrium solidification simulation results based on reliable thermodynamic descriptions/databases ${ }^{[111-115]}$. The best way to calculate the $Q$-value from the thermodynamic models is using the initial slope of the constitutional supercooling $\left(\Delta T_{c s}\right)$ development with a solid fraction $\left(f_{s}\right)$. The growth restriction factor ( $Q$-value) can be expressed as ${ }^{[92]}$ :

$$
Q=\left(\frac{\partial\left(\Delta T_{c s}\right)}{\partial\left(f_{s}\right)}\right)_{f_{s} \rightarrow 0}
$$

in which $\Delta T_{c s}$ is the constitutional supercooling, and $f_{s}$ is the solid fraction. The higher $Q$-values indicate that the solutes can generate the constitutional supercooling at the front of the liquid/solid (L/S) interface, resulting in the refinement of the grain size.

Experimental investigations from different sources ${ }^{[116,117]}$ indicate that there is an inverted relation between the final average grain size $(\bar{d})$ and the value of $Q$. A model is given by Men and Fan ${ }^{[118]}$ demonstrates that the dependence of average grain size on $1 / \mathrm{Q}$ can be described mathematically by a power-law relationship:

$$
\bar{d}=\mathrm{K}\left(\frac{1}{Q}\right)^{1 / 3}
$$

$K$ is a constant that depends on the alloy system, solidification condition, and nucleating particles. For a specific alloy system, the smaller the value of $\mathrm{K}$, the higher the grain refinement efficiency.

\section{Microstructure modification}

The modification of the eutectic structure is also an important way to improve the mechanical properties of aluminum alloy, and the competitive growth of different eutectic structures is the key to modifying the 
eutectic structure ${ }^{[9,9,9,97]}$. Therefore, to study the competitive growth of multiphase structures, it is necessary to thoroughly analyze the solidification of aluminum alloys. It is well known that the CALPHAD method has widely been applied to predict the phase transformation sequence and the evolution of the phase fraction during the solidification process by means of Scheil-Gulliver simulation, which can provide a hint to investigate the modification of the eutectic structure.

The Scheil-Gulliver solidification mode assumes that diffusion in the liquid phase is fast enough to achieve equilibrium while no diffusion exists in the solid phase $(s)^{[119]}$. Such assumptions are roughly applicable to cast aluminum alloys ${ }^{[95]}$. All the solidification information (i.e., phase transition temperatures, phase transition types, and phase/structure fractions) of a specific alloy composition can be obtained by a single Scheil-Gulliver curve. A series of solidification curves can be integrated to construct a diagram of the phase transition temperatures as a function of alloy composition, namely the Scheil-Gulliver solidification diagram $^{[95]}$ or Scheil-Gulliver constituent diagram ${ }^{[120]}$. With such a diagram, the solidification behavior of cast aluminum alloys over a wide composition range can be clearly seen, and the strategy for modification of the eutectic structure(s) can be proposed based on the following criteria ${ }^{[95]}$ : (1) to obtain a larger constitutional undercooling; (2) to realize the competitive growth of different eutectic structures; and (3) to increase the content of $\mathrm{Si}$ in the remaining liquid phase for enhancing the nucleation efficiency of the eutectic $(\mathrm{Si})$.

\section{Physics-based calculations}

Solid solution hardening ${ }^{[121,122]}$ and precipitation strengthening mechanisms ${ }^{[05]}$ are the basis for the development of high-strength aluminum alloys. It is necessary to obtain basic physical parameters (i.e., lattice parameter, electron work function, bonding charge density) of target alloys and to establish their correlation with the mechanical properties (i.e., Young's modulus, hardness, and strength) ${ }^{[8,99]}$. In a target alloy with a relatively high content of alloying elements, the second phase is usually introduced during the refinement and modification process of the casting aluminum alloy, and the uniform dispersion of the hard fine particles plays a vital role in the improvement of the strength and ductility in casting aluminum alloy ${ }^{[123]}$. Therefore, it is vital to determine the modulus of the second phase in aluminum alloys. Based on the critical literature review ${ }^{[124-131]}$, the bulk modulus and shear modulus of a number of precipitated phases in aluminum alloys calculated by FP calculations are given in Table 1. It can be seen from the table that the bulk and shear modulus of some intermetallics (i.e., $\mathrm{Al}_{3} \mathrm{Sc}, \mathrm{TiB}_{2}$, and $\mathrm{AlSc}_{2} \mathrm{Si}_{2}$ ) are much larger than those of $(\mathrm{Si})$ and $(\mathrm{Al})$. Thus, the addition of $\mathrm{TiB}_{2}$ particle or rare-earth $\mathrm{Sc}$ elements can greatly improve the mechanical properties of casting aluminum alloys, which has already been verified by different experiments $^{[30,36]}$.

\section{Heat treatment mechanisms}

The heat treatment process is essential to improve the mechanical properties of casting aluminum alloy, and the heat treatment of casting aluminum alloy mainly includes the solution heat treatment and aging treatment. The purpose of solution heat treatments is to maximize the solubility of solute atoms (i.e., $\mathrm{Mg}, \mathrm{Si}$, $\mathrm{Cu}$, or $\mathrm{Zn})$ in the $(\mathrm{Al})$ matrix, to improve mechanical properties, or prepare for subsequent aging treatment ${ }^{[132]}$. After aging treatment, the hardening precipitates form in supersaturated (Al) solid solution, which further improves the properties of casting aluminum alloys. Generally, two important parameters (i.e., temperature and time) need to be determined for heat treatment. In terms of CT technique, the temperature window of the solution/aging heat treatment can be selected by using the property diagram ${ }^{[133]}$. Then, particle dissolution kinetics can be simulated to further optimize the temperature and time of solution heat treatment ${ }^{[81]}$. Moreover, the precipitation simulation can be performed to estimate the aging heat treatment time considering the effect of the cooling rate ${ }^{[52]}$. 
Table 1. Bulk modulus (B) and shear modulus (G) of different phases in typical aluminum alloys from the literature

\begin{tabular}{|c|c|c|c|c|c|c|c|}
\hline Phases & $\mathrm{B}(\mathrm{GPa})$ & $\mathbf{G}(\mathrm{GPa})$ & Ref. & Phases & $\mathrm{B}(\mathrm{GPa})$ & $\mathbf{G}(\mathrm{GPa})$ & Ref. \\
\hline$(\mathrm{Al})$ & 76.5 & 1 & Garay-Tapia et al. ${ }^{[124]}$ & $\mathrm{TiB}_{2}$ & 276.0 & 252.0 & Dodd et al. ${ }^{[129]}$ \\
\hline$(\mathrm{Si})$ & 94.3 & $\backslash$ & Garay-Tapia et al. ${ }^{[124]}$ & $\mathrm{Al}_{2} \mathrm{CuMg}$ & 75.2 & 48.1 & Li et al. ${ }^{[125]}$ \\
\hline $\mathrm{Al}_{2} \mathrm{Cu}$ & 88.7 & 71.9 & Li et al. ${ }^{[125]}$ & $\mathrm{AlSc}_{2} \mathrm{Si}_{2}$ & 99.9 & 74.1 & Chen et al. ${ }^{[130]}$ \\
\hline $\mathrm{Mg}_{2} \mathrm{Si}$ & 57.9 & 48.8 & Huang et al. ${ }^{[126]}$ & $\mathrm{Al}_{2} \mathrm{Si}_{2} \mathrm{Sr}$ & 45.7 & 40.9 & Garay-Tapia et al. ${ }^{[124]}$ \\
\hline$M g Z n_{2}$ & 59.2 & 19.0 & Li et al. ${ }^{[125]}$ & $\mathrm{AlSi}_{2} \mathrm{La}$ & 69.4 & 44.5 & Pang et al. ${ }^{[131]}$ \\
\hline $\mathrm{Al}_{3} \mathrm{Sc}$ & 86.0 & 68.6 & Chen et al. ${ }^{[127]}$ & $\mathrm{AlSi}_{2} \mathrm{Ce}$ & 80.9 & 36.5 & Pang et al. ${ }^{[131]}$ \\
\hline $\mathrm{Al}_{3} \mathrm{Zr}$ & 120.6 & 87.1 & Li et al. ${ }^{[125]}$ & $\mathrm{AlSi}_{2} \mathrm{Pr}$ & 76.0 & 38.6 & Pang et al..$^{[131]}$ \\
\hline $\mathrm{Al}_{3} \mathrm{Ni}$ & 117.6 & 67.1 & Zheng et al. ${ }^{[128]}$ & $\mathrm{AlSi}_{2} \mathrm{Nb}$ & 80.9 & 54.7 & Pang et al..$^{[131]}$ \\
\hline
\end{tabular}

\section{Data-driven machine learning method and its applications}

Recently, there has been an increasing application of the ML approach in the design of various aluminum alloys to improve their mechanical properties and service performance ${ }^{[134-137]}$. Data is being raised beyond fundamental scientific theory and empirical/semi-empirical material sciences knowledge in a more straightforward way than ever ${ }^{[138,139]}$. However, revealing and reasonably quantifying the intricate principles of material sciences underlying sparse observed scatters with general machine learning techniques/frameworks is still far from realized. Questions are generally reverted to exploring the possible association between materials science problems and specific data-driven approaches. Therefore, insight into the materials science problem of interest and expertise in machine learning approaches are both essential before urging tentative solutions ${ }^{[140-143]}$.

\section{Machine learning toward materials-property relation}

For the ML, datasets, descriptors, and algorithms are the primary components ${ }^{[144]}$. Despite the specific study cases, the dataset is the prerequisite source governed by hiding principles with respect to the specific problem of interest. In general, preparation of the dataset for ML is time-consuming and consists of the workflow of cleaning and curating, where consistency and integrity of data are to be reserved. For a typical "materials $\rightarrow$ property" relation dataset, features related to materials are referred to as input, while the property is referred to as output ${ }^{[140]}$. The task of the ML approach is therefore put forward: what are the potential features/constituents of a novel material that possess the best estimation of the properties of the concerned materials?

The second step is to establish a mapping (descriptors and algorithms) between materials and properties that are entirely numerical in nature and do not require any knowledge of the physical connection involved. Algorithms can be divided mainly into three categories, which are supervised learning, unsupervised learning, and reinforcement learning. Generally, supervised learning is preferred and thus used in classification or regression problems, encompassing support vector machine algorithms, Naive Bayes classifiers, decision trees, neighbor K-nearest algorithms, and artificial neural networks (ANNs) ${ }^{[145,146]}$. Among the various types of learning algorithms, artificial neural networks are widely used in material manufacturing processes due to their ability to overcome the limitations imposed by nonlinearities and the multiple parameters involved in computing material design problems ${ }^{[147-150]}$.

As an important step toward achieving material discovery/design, FP calculations based on density functional theory (DFT), have been widely applied to predict crystal structures, basic physical properties, and fundamental electronics ${ }^{[100,101]}$. The ML method not only offers great convenience for data acquisition and analysis but also builds the correlation between basic physical parameters and mechanical properties to assist material discovery/design ${ }^{[151,152]}$. Moreover, the combination of ML method and FP calculation 
stimulates the development of materials simulations. Recently, the ML method has been used to develop the atomistic potentials that can boost the computational efficiency of first-principles methods by order of magnitude without affecting the accuracy in, i.e., $\mathrm{Al}-\mathrm{Mg}^{[153]}, \mathrm{Al}-\mathrm{Cu}^{[154]}$, and $\mathrm{Al}-\mathrm{Si}-\mathrm{Mg}$ alloys ${ }^{[155]}$. Meanwhile, the integration of FP calculations and the ML method to achieve high-throughput calculations and storage of data is also one key for material theory design ${ }^{[156-160]}$. For example, Wang et al.$^{[156]}$ studied the power-law scaled hardness of solute strengthened nonequilibrium solid solutions. The electronic properties (i.e., electron work function, Fermi energy, bonding charge density, and lattice parameter) were derived from high-throughput FP calculations, and the atomic and electronic insight into the composition-structureproperty relationships was revealed by the ML method.

\section{Problem-oriented machine learning for material design}

For new researchers eager to use the ML method, the most important question may be whether this method can solve their problem ${ }^{[151]}$. Preliminarily, a reliable dataset is expected to be available due to efforts to generate a critical subset in a controlled manner. Moreover, the question remains whether or not the problem of interest is interpretable with the ML approach. In summary, data-driven ML methods should be aimed at (1) properties that are very difficult or expensive to compute or measure using traditional methods; (2) phenomena that are too complex for a straightforward solution based on fundamental equations to be hard to be resolved; or (3) phenomena in which the governing equation is out of the scope of knowledge, serving as the rationale for the exploration of surrogate models. Machine learning might also be responsible for refining the essential features behind repetitive but expensive operations, especially when interpolations are needed in high-dimensional spaces, such as when properties are fit into large chemical and/or configurational spaces ${ }^{[152]}$.

It is different from optimizing the casting aluminum alloys through intuition and the trial-and-error method because of the complexity in their numerous processing steps and wide composition range. The ML techniques have attracted particular interest in the aided design of multicomponent alloys. Recently, a new type of $\mathrm{Al}-\mathrm{Zn}-\mathrm{Mg}-\mathrm{Cu}$ alloy with the desired UTS was designed by Li et al. ${ }^{[135]}$ according to the composition and process optimization using the machine learning technique. Their results demonstrate that it is feasible to use machine learning to search $\mathrm{Al}-\mathrm{Zn}-\mathrm{Mg}$-Cu alloys with good mechanical properties. Combined with the reported experimental data published in the literature with the machine learning design system (MLDS), the composition-property relation of Al- $\mathrm{Zn}-\mathrm{Mg}$-Cu alloys was constructed by Jiang et al. ${ }^{[161]}$, and the alloy composition that met the required mechanical properties were obtained. Furthermore, the hardening and toughening mechanisms of the novel aluminum alloy were also analyzed and verified by key experiments.

\section{To be strategically situated: synergy between $\mathrm{CT}$ and $\mathrm{ML}$ approaches}

The CT-driven alloy design approach for casting alloys starts from accurate equilibrium phase diagram calculations and Scheil-Gulliver solidification simulations based on a reliable thermodynamic database and results in the quantitative relation of "Composition - Process - Microstructure" of the target alloys ${ }^{[95,162]}$. However, for a successful alloy design, some qualitative/empirical relations of "microstructure - properties" should be known beforehand, as is one serious disadvantage for the CT-driven alloy design approach. Fortunately, with an appropriate dataset and model, the ML technique can efficiently predict the properties of specific components, serving as the bridge for the quantitative relation of "Microstructure Properties"[146]. Thus, with a combination of the CT and ML approaches, the quantitative relation of "Composition - Process - Microstructure - Properties" for the target alloys can be effectively established, from which the alloy composition and manufacturing process can be optimized. The schematic diagram of the computational alloy design approach by combining CT and ML techniques is shown in Figure 3. 


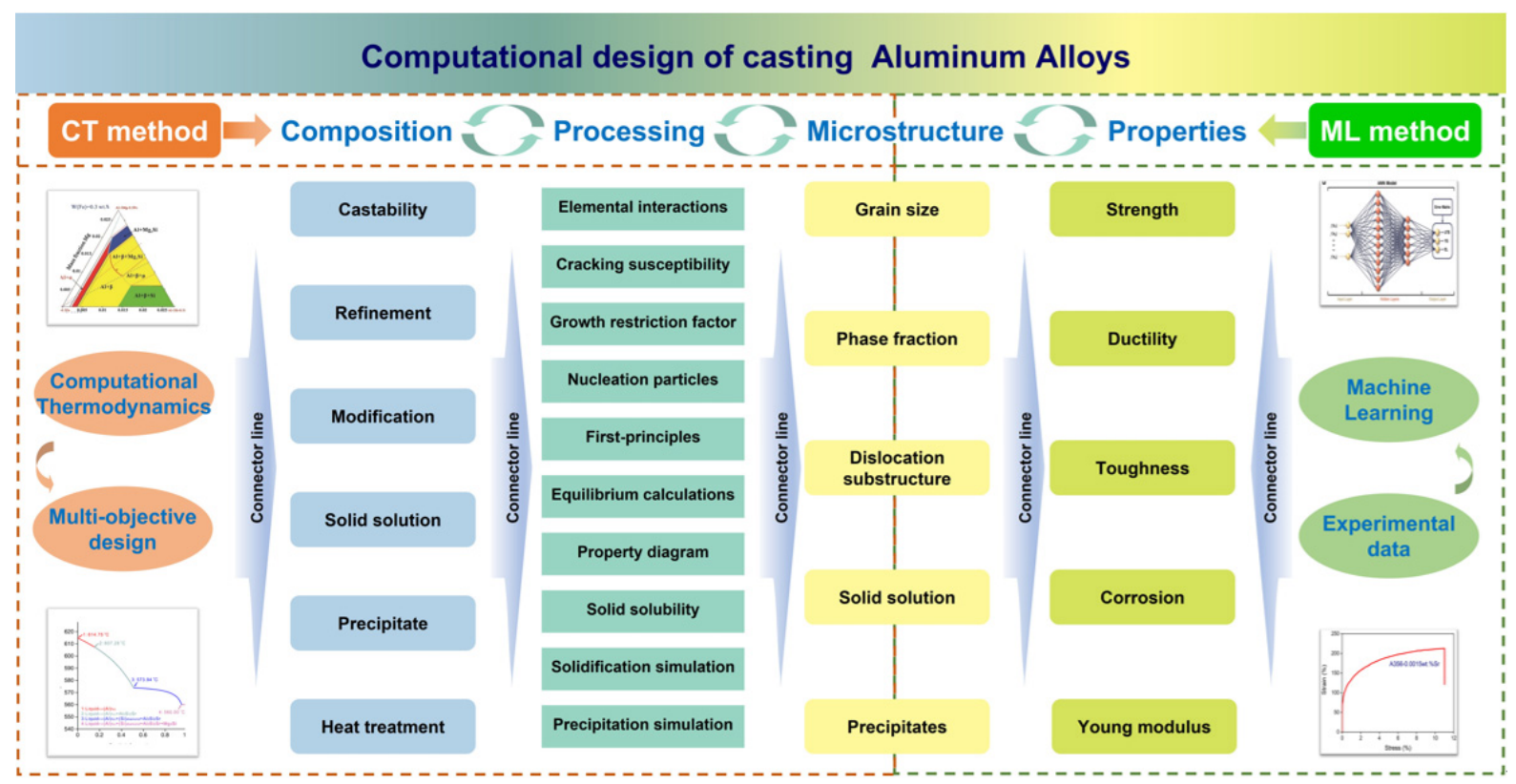

Figure 3. Schematic diagram for the efficient computational alloy design approach by combining computational thermodynamic and machine learning techniques.

First, based on the reliable thermodynamic database of the target aluminum alloy, the equilibrium phase diagram and property diagrams with a wide range of components can be calculated by using thermodynamic software (e.g., Thermo-Calc ${ }^{[163]}$, Pandat ${ }^{[164]}$, FactSage ${ }^{[165]}$, and MTDTA ${ }^{[166]}$ ), and the thermally stable phase region and phase transformation information are obtained. Moreover, the solid solubility of alloying elements in the matrix and the variation of phase fractions with temperature and composition are provided $^{[167]}$. Second, the solidification process of a target aluminum alloy with different components can be simulated by the Scheil-Gulliver solidification mode, resulting in quantitative solidification behaviors such as the phase transition temperature, solidification sequence, and volume fraction of the precipitated phase $^{[95]}$. The influence of solute elements on the grain size and castability of the target aluminum alloy can then be analyzed through the calculation of the growth restriction factor and cracking susceptibility index, respectively. Third, the quantitative relation among alloy composition, temperature, and microstructures can be established according to thermodynamic calculation ${ }^{[162]}$. Fourth, the calculated/simulated results and the experimental data are sorted in a machine learning dataset, and the appropriate models can be selected to establish the quantitative relation among the composition, process, microstructure, and mechanical properties of the target aluminum alloy, from which the alloy composition and process parameters can be optimized/designed ${ }^{[168]}$. Finally, key experiments are carried out to validate the accuracy of the designed results.

\section{THERMODYNAMIC DATABASES FOR ALUMINUM ALLOYS}

\section{Available commercial/public thermodynamic database}

The key to performing computational alloy design through CT lies in the accuracy of the thermodynamic database. The thermodynamic databases of multicomponent aluminum alloys have been under development for many years. Currently, several commercial/public databases are available for aluminum alloys, including COST507 ${ }^{[169]}$, TTAL ${ }^{[170]}$, FTlite ${ }^{[171]},{\mathrm{ME}-\mathrm{Al}^{[172]} \text {, TCAL }}^{[173]}$, and PanAl ${ }^{[177]}$. Among them, $\mathrm{TCAL}^{[173]}$ and PanAl ${ }^{[174]}$ are the most widely used thermodynamic databases of multicomponent aluminum alloys. 
The TCAL database was originally released by Thermo-Calc in May 2011 and contained a thermodynamic description of the Al-Cu-Fe-Mg-Mn-Ni-Si-Zn system ${ }^{[76]}$. In 2021, Thermo-Calc released the latest version of the TCAL database (TCAL8). The thermodynamic descriptions of $\mathbf{4 4}$ pure elements, 275 binary systems, 108 ternary systems, and $\mathbf{1 4}$ quaternary systems were assessed in the TCAL8 database ${ }^{[173]}$. Moreover, the database contains additional property data such as the surface tension of the liquid, the viscosity of the liquid, thermal conductivity, electrical resistivity, and molar volume. The TCAL database has been widely used in various studies on aluminum alloys due to its excellent accuracy in phase equilibria calculations $^{[175-177]}$.

With financial support from the United States Air Force Research Laboratory through Small Business Innovation Research program. CompuTherm began developing the PanAl thermodynamic database in 2000 and released the first version with 17 components in $2004^{[178,179]}$. After 21 years of development, the PanAl database has extended to include 37 components, 1033 phases, 415 binary systems, and all the Al- $W-V(W$ and $V$ represent $\mathrm{Cu}, \mathrm{Fe}, \mathrm{Mg}, \mathrm{Mn}, \mathrm{Si}$, and $\mathrm{Zn}$ major alloying elements) ternary systems ${ }^{[174]}$. In addition, the PanAl database includes the atomic mobility and molar volume descriptions of multicomponent aluminum alloys, which can be used to simulate the precipitation and growth of aluminum alloys.

\section{Beyond the thermodynamic database}

For newly developed material, if commercial databases are unavailable or inaccurate, a custom thermodynamic database needs to be developed ${ }^{[75]}$. Central to the established thermodynamic database is the CALPHAD method. The quintessence is indicated in Figure 4. The thermodynamic properties obtained from experimental studies/first-principles calculations and phase equilibrium/transformation data determined by experiments were collated, and the two classes of data were combined under the framework of the CALPHAD method. Each phase in the research system corresponds to a unique set of Gibbs energy functions related to temperature, pressure, and composition. The multiphase and multicomponent phase equilibria are then calculated by minimizing the Gibbs energy of the system at a constant temperature, pressure, and composition ${ }^{[73]}$. Such minimizer is available in all the current thermodynamic software packages, such as Thermo-Calc ${ }^{[163]}$, Pandat ${ }^{[164]}$, and Factsage ${ }^{[165]}$. Therefore, the previously separated classes of data are unified into a dataset unique to the CALPHAD method; each phase in the dataset has specific Gibbs energy models and corresponding thermodynamic parameters. On the whole, for multicomponent systems, this constitutes a thermodynamic database, such as the TCAL and PanAl databases.

Driven by the rapid increase in available computational data and a large number of data repositories, the integration of FP calculations based on DFT and CALPHAD accelerated material thermodynamic database development ${ }^{[158]}$. Beyond the thermodynamic properties, HTCs of DFT provide more fundamental information (i.e., phase stability, lattice parameter, Poisson's ratio, electron work function, bonding charge density, and so on) to obtain unique/universal principles/criteria/figures for material design ${ }^{[160]}$.

Compared with the experimental measurements, DFT calculations significantly reduce the time required to obtain thermochemical data but still require considerable computer resources and time for each calculation. Moreover, the number of calculations needed for a phase increases exponentially with the number of sublattices and components ${ }^{[70]}$. It is necessary to develop a new generation of software tools that support automated model selection, parameter optimization, and database development. Fortunately, the software package, Extensible Self-optimizing Phase Equilibria Infrastructure, which is built on DFT data developed by Bocklund et al. ${ }^{[180]}$, offers a free and open-source tool for users to develop multicomponent databases. When the subsystem is updated, the thermodynamic parameters of the higher-order systems can be efficiently reevaluated, which reduces the time of database development. 


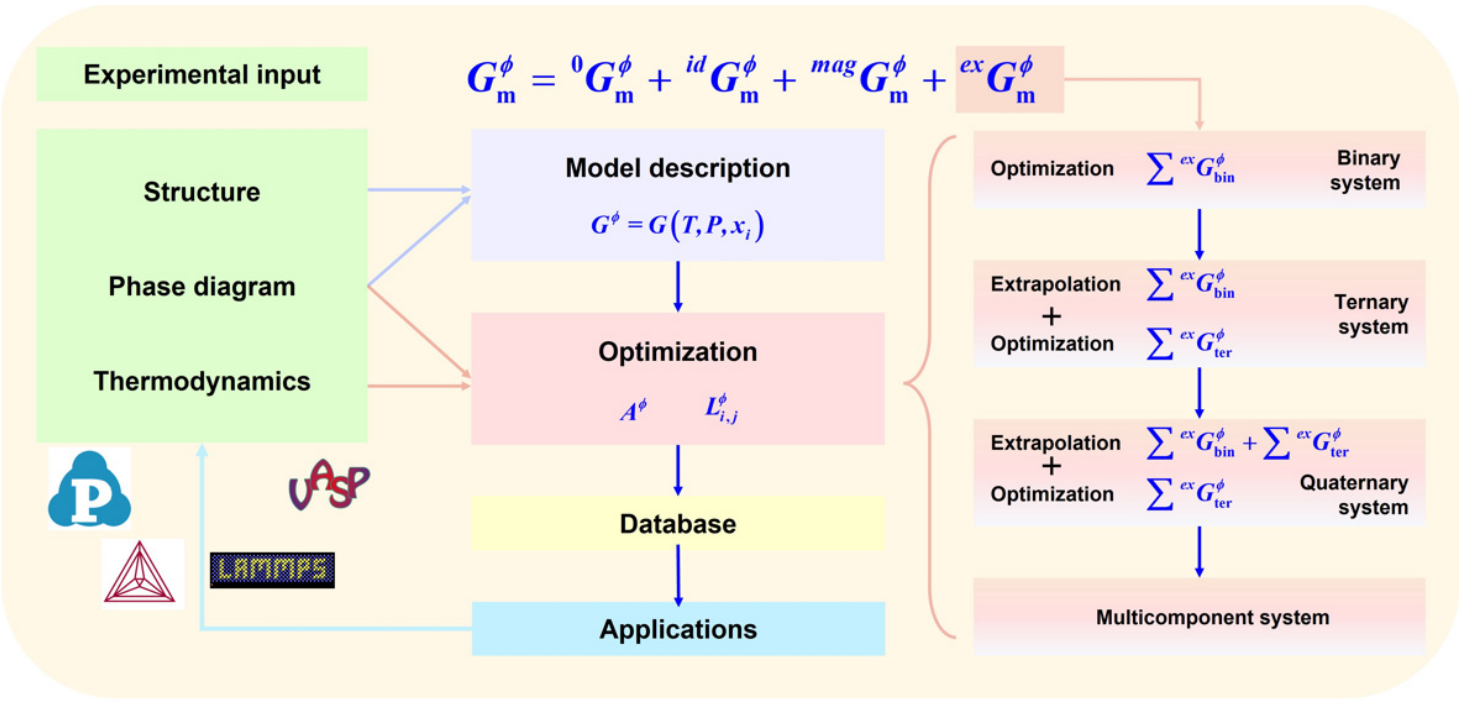

Figure 4. Flowchart of establishing the thermodynamic database in the framework of CALPHAD technique.

\section{CASE STUDIES ON COMPUTATIONAL DESIGN OF CASTING ALUMINUM ALLOYS DRIVEN BY CT, ML AND THEIR COMBINATIONS \\ Common applications of CT/ML techniques in different aluminum alloys}

In recent decades, the CT technique has been widely used to study phase equilibria, predict the hot cracking susceptibility, analyze grain refinement/modification, understand heat treatment mechanisms, and so on, which may serve as a solid basis for the computational design of multicomponent aluminum alloys.

As is well known, it is crucial to understand the elemental interaction before alloy design. Selection of suitable alloying elements and determination of the composition range are necessary steps to avoid the formation of harmful phases. Lu et al. ${ }^{[167]}$ developed a high-performance Al-Fe-Mg-Si alloy by selecting stable phase regions, screening alloy elements, and determining the atomic ratio. As shown in Figure 5A, the isothermal section calculation at $550{ }^{\circ} \mathrm{C}$ of the $\mathrm{Al}-\mathrm{Fe}-\mathrm{Mg}$-Si system was used to design the $\mathrm{Mg} / \mathrm{Si}$ atomic ratio in this system. To ensure the full dissolution of $\mathrm{Mg}$ and $\mathrm{Si}$ atoms in the ( $\mathrm{Al}$ ) matrix, the phase region with the $\mathrm{Mg}_{2} \mathrm{Si}$ and $\beta$-AlFeSi phases should be avoided. Therefore, the alloy composition should be in the red area in Figure $5 \mathrm{~A}$, with the $\mathrm{Mg} / \mathrm{Si}$ atomic ratio being between $1: 1$ and 2:1, set at 1.5:1 in their work. Combined with the calculated vertical section of the Al-Fe-Mg-Si system shown in Figure 5B, $\beta$-AlFeSi exists when the temperature is below $595{ }^{\circ} \mathrm{C}$. Since the formation of $\beta$-AlFeSi cannot be avoided by adjusting the solution temperature, the addition of other elements, such as $\mathrm{Mn}$ or $\mathrm{Cu}$, is a better choice to avoid the formation of $\beta$-AlFeSi.

For casting aluminum alloys, castability is an important criterion to evaluate the properties of alloys. The crack susceptibility index of aluminum alloy provides useful information for avoiding the selection of alloy components that are the most prone to cracking. Liu and $\mathrm{Kou}^{[89]}$ evaluated the crack susceptibility index map of $\mathrm{Al}-\mathrm{Cu}-\mathrm{Mg}$ systems with different $\mathrm{Cu}$ and $\mathrm{Mg}$ contents at three levels of back diffusion, i.e., no back diffusion [Figure $6 \mathrm{~A}$ ], back diffusion under a cooling rate of $100^{\circ} \mathrm{C} / \mathrm{s}$ [Figure $6 \mathrm{~B}$ ], and back diffusion under a cooling rate of $20^{\circ} \mathrm{C} / \mathrm{s}$ [Figure $6 \mathrm{C}$ ]. The locations of high crack susceptibility regions were compared with those observed in the experimental crack susceptibility tests [Figure $6 \mathrm{D}$ ]. The calculated results with back diffusion considered, with a cooling rate of either $20^{\circ} \mathrm{C} / \mathrm{s}$ or $100{ }^{\circ} \mathrm{C} / \mathrm{s}$, are in good agreement with the measured values, indicating that the influence of back diffusion on the crack sensitivity can be evaluated by 

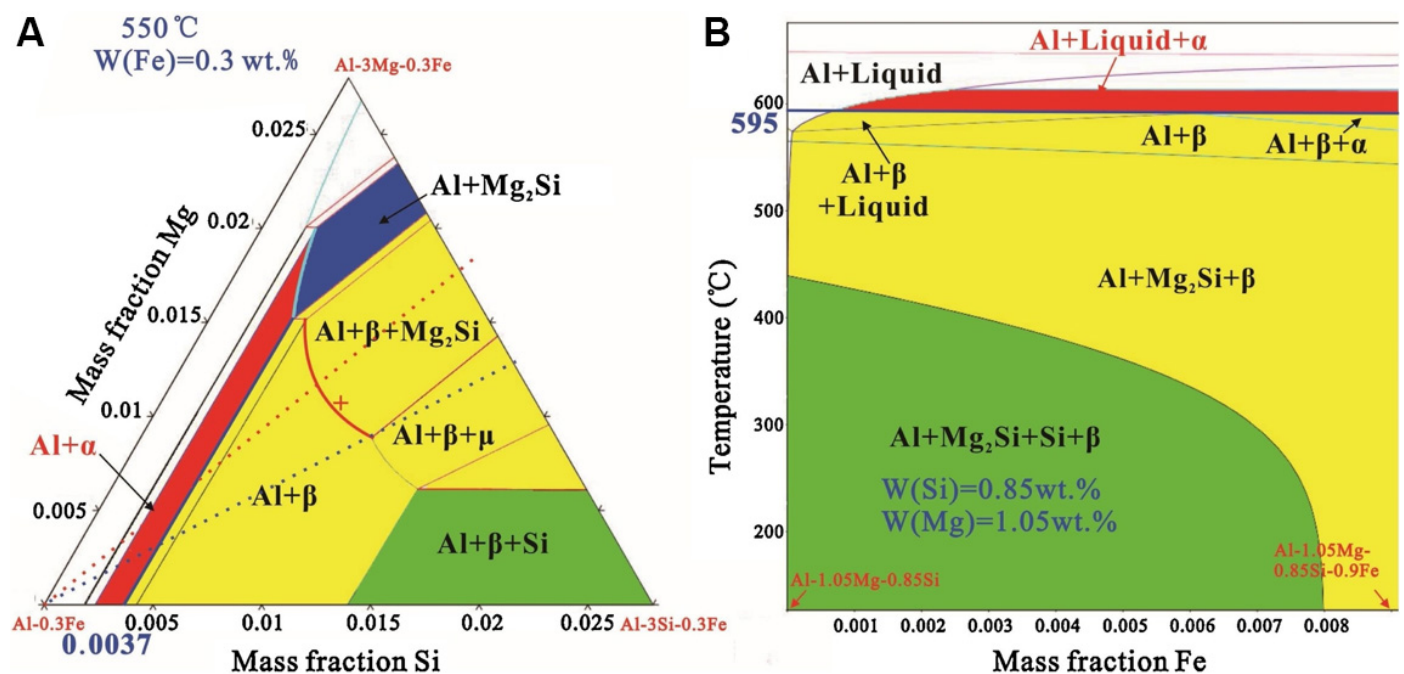

Figure 5. Calculated phase diagrams of the Al-Fe-Mg-Si system: (A) quasi-ternary isothermal section with fixed iron content of $0.3 \mathrm{wt} \%$ at $550^{\circ} \mathrm{C}$. The $\mathrm{Mg} / \mathrm{Si}$ atomic ratios of red and blue dotted lines are 2:1 and 1:1, respectively. The red cross is the composition with the same contents of $\mathrm{Mg}$ and $\mathrm{Si}$ as the finally designed alloy. (B) Vertical section of $\mathrm{Al}-1.05 \mathrm{Mg}-0.85 \mathrm{Si}-x \mathrm{Fe}$ (in wt\%). Figure reproduced from Ref. ${ }^{[167]}$ with permission from Elsevier.

crack sensitivity index.

Modifying the microstructure of the target alloy is an efficient means to improve its properties. To design ultrafine hypoeutectic Al-Cu-Si-Mg alloy with high performance, the solidification paths of Al- $x \mathrm{Cu}-2.2 \mathrm{Si}$ $1.0 \mathrm{Mg}(x=5,6.6$, and 10.6 wt $\%)$ alloys with $20 \%, 25 \%$ and, $30 \%$ eutectic mixtures were simulated by Cai et al. ${ }^{[181]}$ by using the CT approach, as shown in Figure 7, the additional $\mathrm{Cu}$ content can significantly influence the solidification sequences of $\mathrm{Al}-x \mathrm{Cu}-2.2 \mathrm{Si}-1.0 \mathrm{Mg}$ alloys. When the $\mathrm{Cu}$ content was 5.0 and 6.6, there were four reactions in the alloys as the temperature decreased. In contrast, when the Cu content increases to 10.6, there are only three reactions in the alloys. They argued that the $\mathrm{Al}-10.6 \mathrm{Cu}$ alloy with the most eutectic mixture had the highest strength. Furthermore, the key experiments confirmed that the YS and UTS increase with increasing eutectic fraction.

Most aluminum alloys are heat treatable; it is necessary to study the heat treatment mechanisms by the CT technique. Recently, based on the TCAL thermodynamic database, the heat treatment mechanisms of aluminum alloys were studied in detail by Chen et al. ${ }^{[182]}$, as shown in Figure 8. First, the solution heat treatment temperature of the Al-0.82Si-0.55Mg-0.016 Cu-0.5Mn-0.2Fe (in wt\%) alloy was screened by the property diagram [Figure $8 \mathrm{~A}$ ]. When the temperature is higher than $440{ }^{\circ} \mathrm{C}$, the $\mathrm{Al}_{9} \mathrm{Fe}_{2} \mathrm{Si}_{2}$ phase is completely dissolved in the (Al) matrix. To maximize the solubility of $\mathrm{Mg}$ and $\mathrm{Si}$ in the (Al) matrix to form hardening precipitates, the solution temperature should be above $510^{\circ} \mathrm{C}$. It is worth mentioning that the $\mathrm{Al}_{15} \mathrm{Si}_{2} \mathrm{M}_{4}$ phase cannot be completely dissolved in the (Al) matrix of this system, although the amount of $\mathrm{Al}_{15} \mathrm{Si}_{2} \mathrm{M}_{4}$ phase decreases with increasing temperature. Moreover, a higher solution temperature leads to higher energy consumption. Therefore, a solution temperature of $530{ }^{\circ} \mathrm{C}$ seemed to be a good choice and was thus used in experiments ${ }^{[183]}$. Second, the kinetics of particle dissolution were used to estimate the solution time of aluminum alloy. For instance, the dissolution behavior of ( $\mathrm{Si}$ ) particles in $\mathrm{Al}-0.8 \mathrm{Si}$ (in wt\%) alloy at different temperatures and time is presented in Figure $8 \mathrm{~B}$, and the volume fraction of (Si) particles decreases with the increase of time. It is worth noting that when the solution temperature is $500{ }^{\circ} \mathrm{C},(\mathrm{Si})$ particles cannot be completely dissolved. When the solution temperature was $530^{\circ} \mathrm{C}$ and $560{ }^{\circ} \mathrm{C},(\mathrm{Si})$ particles completely dissolved in the $(\mathrm{Al})$ matrix at $10^{3} \mathrm{~s}$ and $3.5 \cdot 10^{3} \mathrm{~s}$, respectively. Finally, the aging 


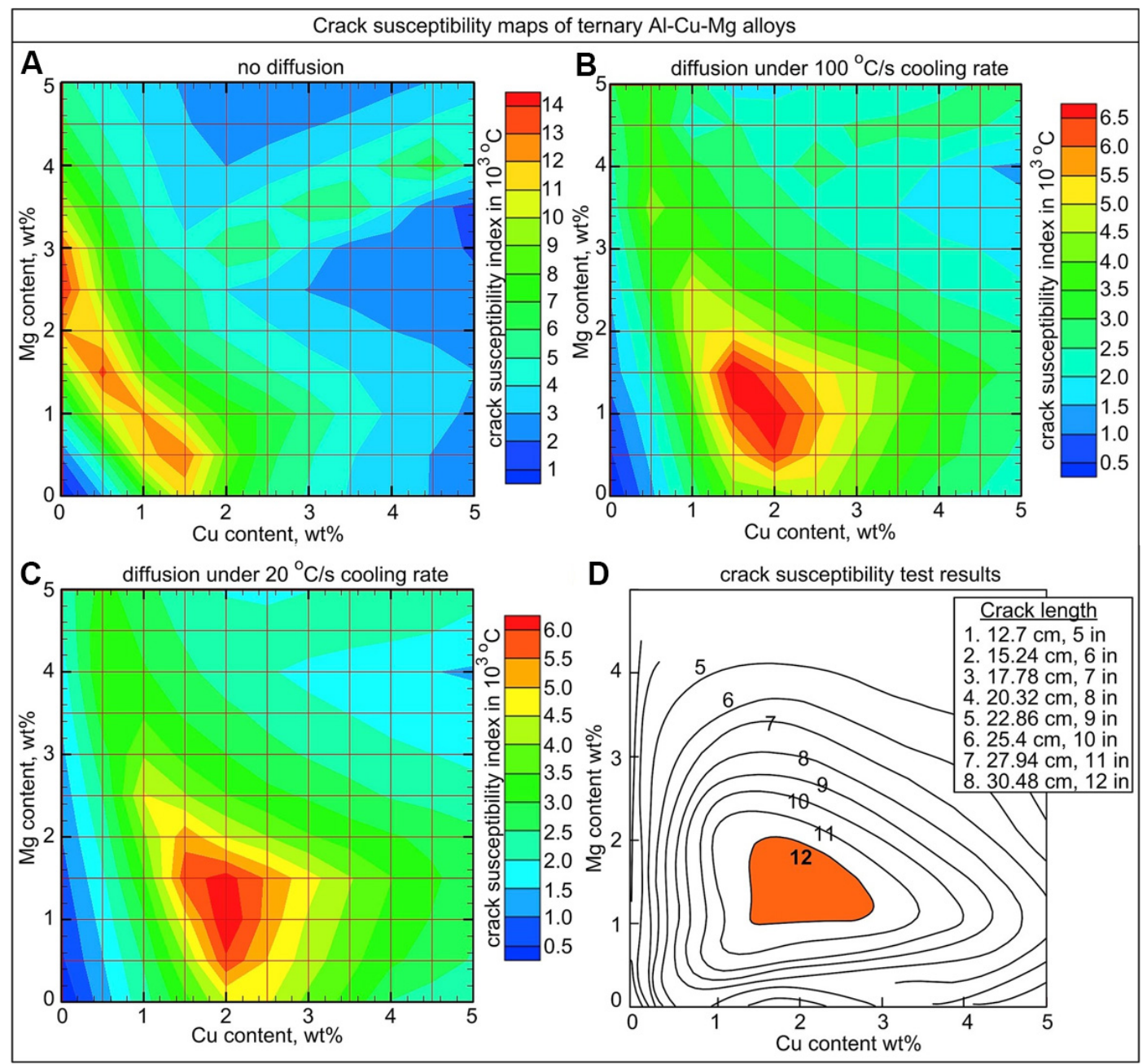

Figure 6. Al-Cu-Mg crack susceptibility maps: (A) without diffusion; (B) with diffusion under $100^{\circ} \mathrm{C} / \mathrm{s}$ cooling rate; (C) with diffusion under $20^{\circ} \mathrm{C} / \mathrm{s}$ cooling rate; (D) based on experimental crack susceptibility tests. High susceptibility region $\left(>5000^{\circ} \mathrm{C}\right)$ in $(\mathrm{C})$ is close to region 12 in (D). Figure reproduced from Ref. ${ }^{[89]}$ with permission from Elsevier.
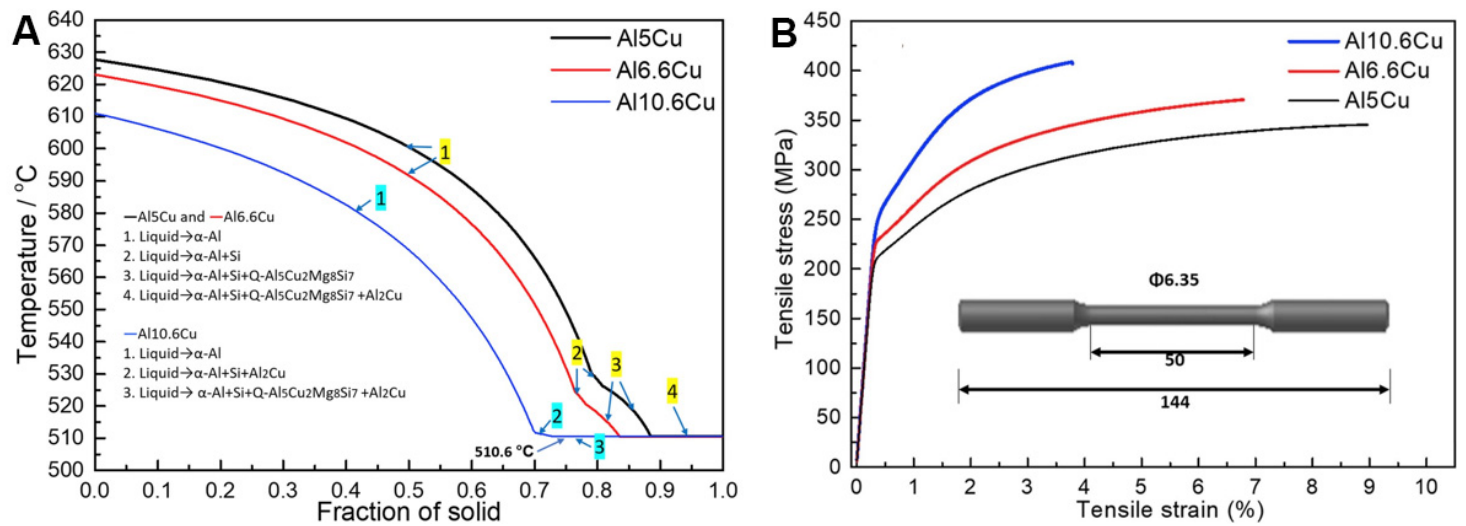

Figure 7. Simulated solidification path (A) and tensile stress-strain curves (B) of die-casting quaternary Al- $x \mathrm{Cu}-2.2 \mathrm{Si}-1.0 \mathrm{Mg}(x=5,6.6$, and $10.6 \mathrm{wt} \%$ ) alloys. Figure reproduced from Ref. ${ }^{[181]}$ with permission from Elsevier. 

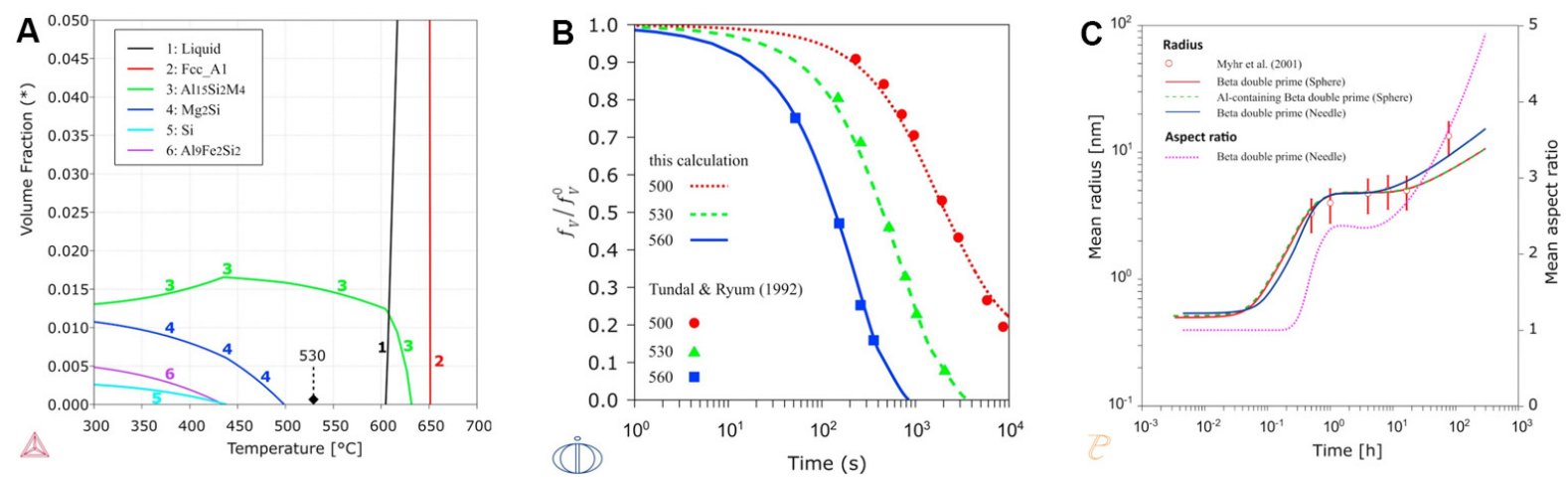

Figure 8. CALPHAD method aided the design of heat treatment process in aluminum alloys: (A) property diagram selected the solution heat treatment temperature of $\mathrm{Al}-0.82 \mathrm{Si}-0.55 \mathrm{Mg}-0.016 \mathrm{Cu}-0.5 \mathrm{Mn}-0.2 \mathrm{Fe}$ (in wt\%) alloy; (B) DICTRA simulation the dissolution kinetics of Si particle in Al-0.8Si (in wt\%) alloys at different temperatures; (C) TC-PRISMA simulated the precipitates of $\beta^{\prime \prime}$ in aluminum alloy. Figure reproduced from Ref. ${ }^{[182]}$ with permission from Elsevier.

treatment time can be designed through the precipitation simulation. Figure $8 \mathrm{C}$ shows that the radius and aspect ratio of the $\beta$ " phase in the $\mathrm{Al}-0.93 \mathrm{Mg}-0.61 \mathrm{Si}-0.26 \mathrm{Fe}$ (in wt\%) alloy were predicted by precipitation simulation, and the aging treatment time of this alloy was estimated to be $3.5 \mathrm{~h}$. In conclusion, the property diagram calculations, dissolution kinetic simulations, and precipitation simulations can provide theoretical guidance for the precise design of the heat treatment process.

Nowadays, the data-driven machine learning method is an effective strategy for the quantitative analysis of aluminum alloys. Jiang et al. ${ }^{[161]}$ designed the ultra-strength and high-toughness aluminum alloys with a property-oriented design strategy based on the ML technique, as shown in Figure 9. First of all, an ML dataset containing 171 groups of reported alloy composition - property data was established. Then, an MLDS was established to train the relationship between composition and properties, and the alloy composition that met the required ductility and toughness was obtained. Finally, three key alloys were prepared and compared with current state-of-the-art $\mathrm{Al}-\mathrm{Zn}-\mathrm{Mg}-\mathrm{Cu}$ alloys. The results show that the alloys predicted by the ML technique exhibit higher comprehensive performance, which proved the capability of the ML technique in the accelerated discovery of high-performance aluminum alloys.

\section{CT-driven design of Sc-additional casting Al-Si-Mg alloys}

Alloying/microalloying has become the most promising strategy for microstructure modification and the improvement of the mechanical properties in Al-Si-Mg casting alloys, among which the element scandium (Sc) is especially powerful ${ }^{[36]}$.

Very recently, Lu and Zhang ${ }^{[95]}$ performed a CT-driven design of the optimal amount of Sc in A356 alloys, as shown in Figure 10. First, a reliable thermodynamic database for the Al-rich Al-Si-Mg-Sc quaternary system was established by using the CALPHAD method, and the solidification paths of A356 alloys with different Sc contents were simulated, from which a solidification diagram of A356- $x$ Sc alloys was constructed to examine the influence of Sc levels on the solidification sequences, solidified microstructure, and constitutional supercooling of cast A356 alloys. In combination with the quantitative relationship between the composition and microstructure of A356- $x \mathrm{Sc}$ alloys and its qualitative relationship with mechanical properties, it was determined that the A356-0.54Sc(wt\%) alloy had the best microstructure and mechanical properties, which was confirmed by subsequent experiments. 

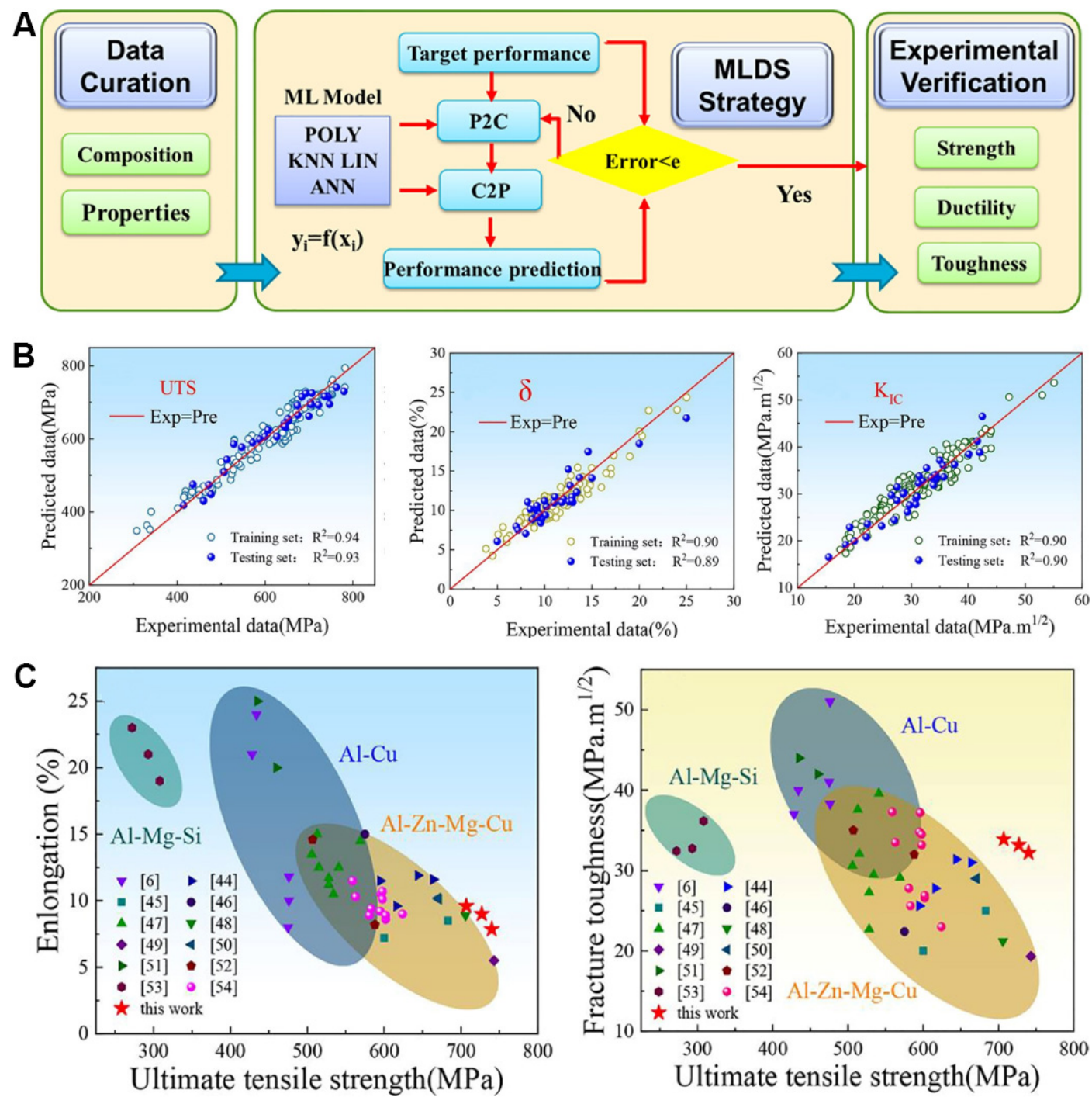

Figure 9. Discovery of aluminum alloys with ultra-strength and high-toughness via a property-oriented design strategy: (A) rational design approach of novel aluminum alloys with ultra-strength and high-toughness; (B) training results composition to property model; (C) comparison of comprehensive properties between the novel ultra-strength and high-toughness aluminum alloys and the existing high-strength and high-toughness aluminum alloy. Figure reproduced from Ref. ${ }^{[161]}$ with permission from Elsevier.

Moreover, the successful application in Sc-additional A356 alloy indicates that the established thermodynamic database of the Al-Si-Mg-Sc quaternary system should be reliable over a wide range of components, which may cover all Al-Si-(Mg) casting alloys ${ }^{[162]}$. As presented in Figure 11, four typical solidification diagrams (i.e., A356-xSc, A357-xSc, A360-xSc, and A380-Sc) were constructed by a large number of Scheil-Gulliver solidification curves, from which the optimal Sc content in a series of hypoeutectic $\mathrm{Al}-\mathrm{Si}-(\mathrm{Mg})$ alloys with the best mechanical properties was determined, and validated by solidified microstructure measurements and mechanical property analysis.

Furthermore, the underlying strengthening and toughing mechanisms for Sc-modified Al-Si-Mg casting alloys were proposed by Lu et al. ${ }^{[162]}$. As displayed in Figure 12, the refinement of the eutectic (Si) plays an important role in the enhancement of the alloy strength and ductility. Second, the appearance of fine hardening $\mathrm{AlSc}_{2} \mathrm{Si}_{2}$ particles by the addition of Sc was another reason for the strengthening and toughing of 


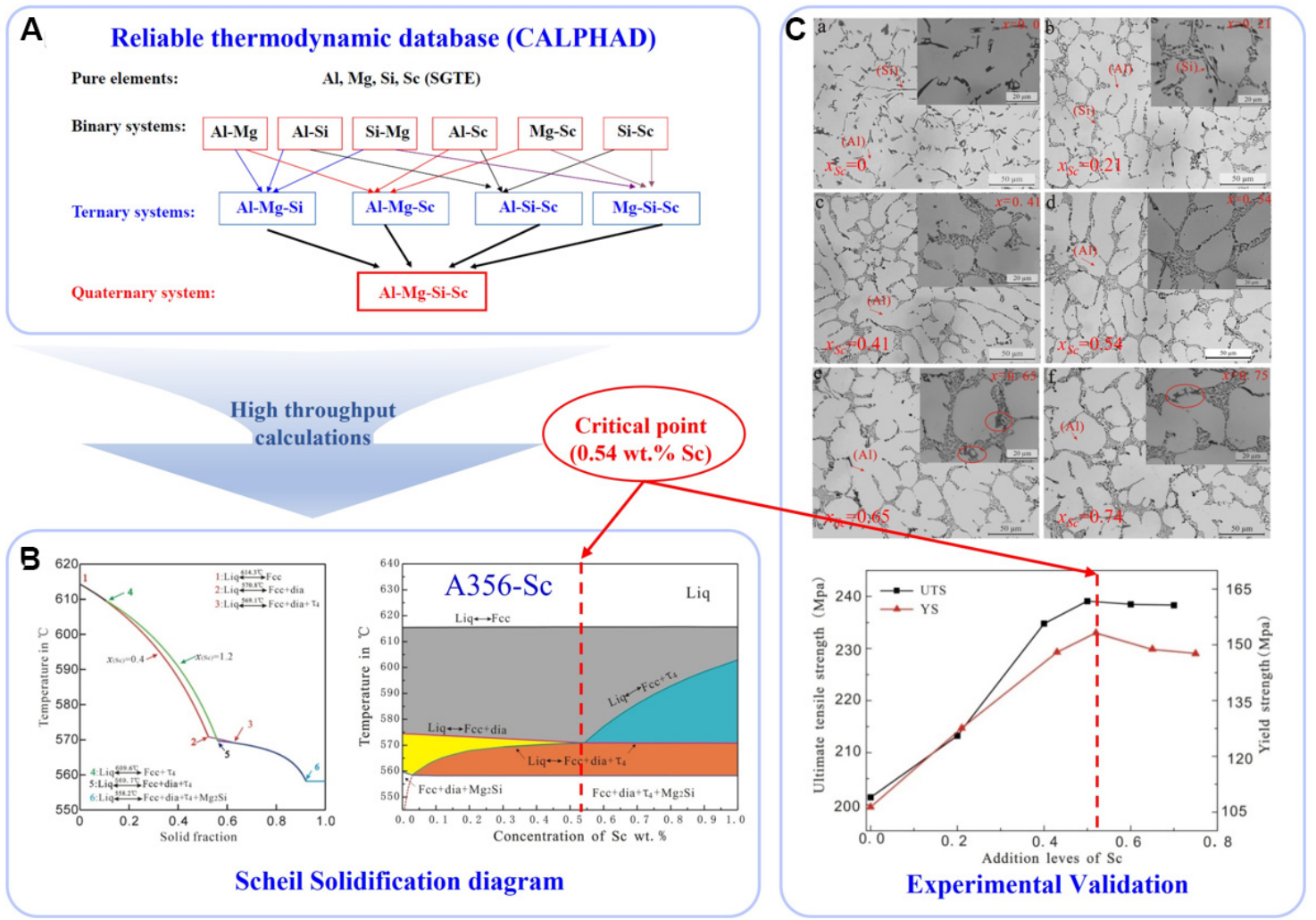

Figure 10. Computational alloy design of Sc-additional A356 cast alloys driven by CT approach. (A) Schematic diagram of the thermodynamic database of the Al-Si-Mg-Sc quaternary system; (B) the solidification curve and diagram of Sc-additional A356 alloy; (C) microstructures and mechanical properties of Sc-additional A356 alloys. Figure reproduced from Ref. ${ }^{[95]}$ with permission from Elsevier.
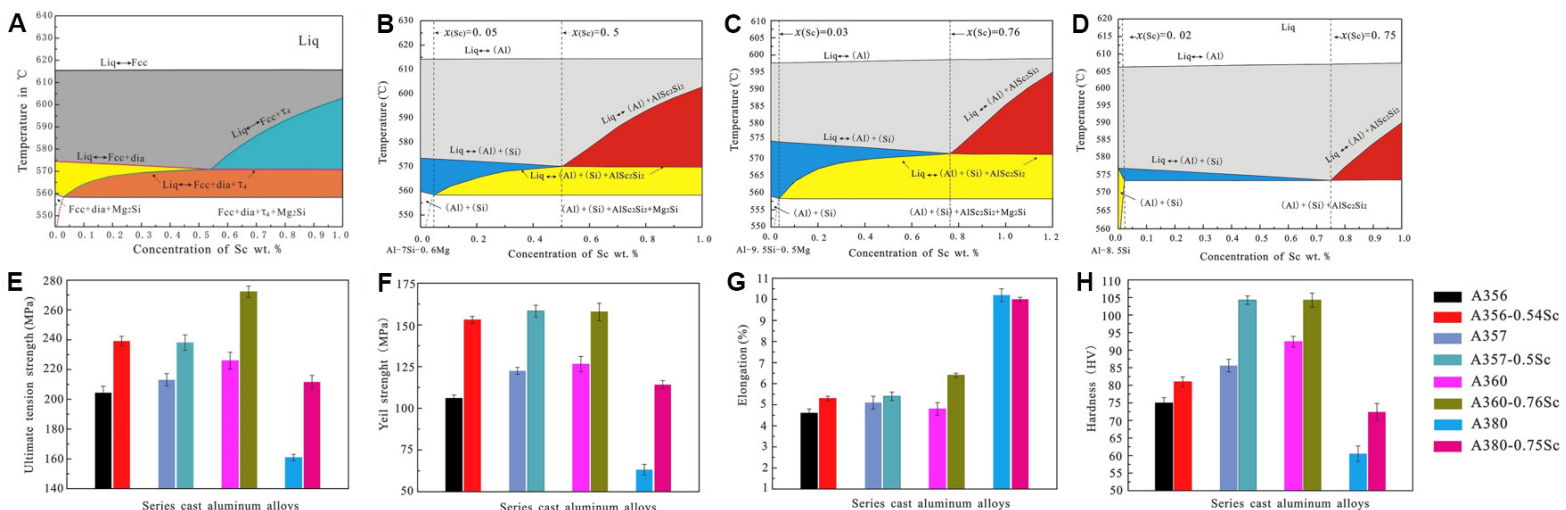

Figure 11. High-throughput design and experimental verification of Sc-additional Al-Si-Mg series casting alloys due to the CT approach: (A-D) are the solidification diagrams of A356-xSc, A357-xSc, A360-xSc, and A380-xSc, respectively; (E-H) are the ultimate strength, yield strength, elongation and hardness of Sc-additional casting aluminum alloys, respectively. Figure reproduced from Ref. ${ }^{[162]}$ with permission from Elsevier.

Al-Si-Mg casting alloys. Last but not least, the high density of dislocations at the grain boundaries due to the occurrence of a partially coherent $\mathrm{AlSc}_{2} \mathrm{Si}_{2}$ phase with the (Al) matrix leads to an improvement in the mechanical properties of Sc-modified Al-Si-Mg alloys. 

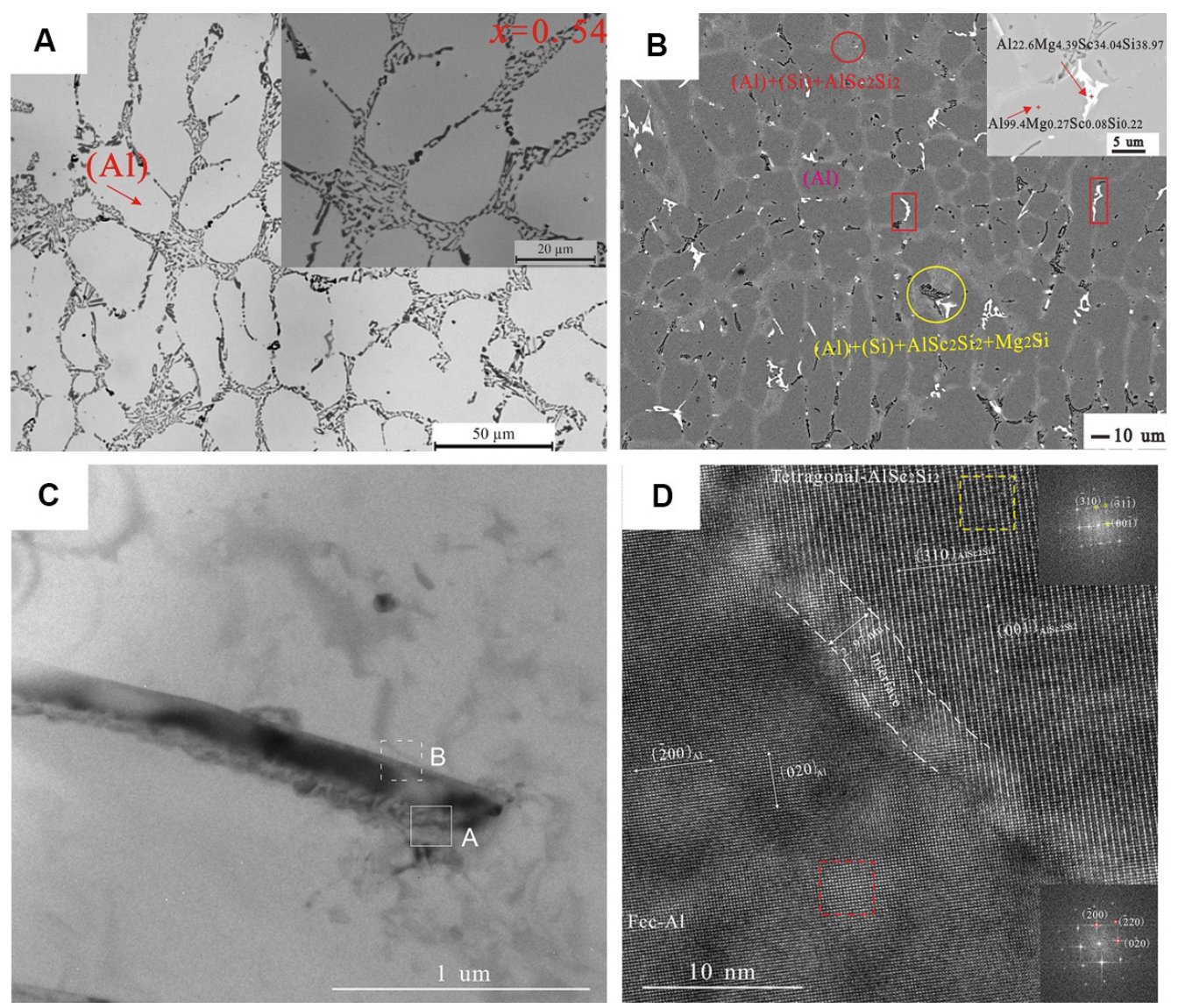

Figure 12. (A) OM image of A356-0.54Sc (wt\%); (B) BES image of A357-0.5Sc alloy (wt\%); (C) TEM bright field image of the primary(Al)/AlSc $\mathrm{Si}_{2}$ /eutectic-(AI); (D) HRTEM image of A region marked with white box in (C). Figure reproduced from Ref. ${ }^{\left[{ }^{91,162]}\right.}$ with permission from Elsevier.

To further improve the mechanical properties of Sc-modified A356 cast alloys, it is necessary to optimize the heat treatment mechanisms. Based on the thermodynamic database of the Al-Si-Mg-Sc quaternary system established by Lu and Zhang ${ }^{[95]}$, the property diagram of A356-0.54Sc alloy was calculated by Liu et al. ${ }^{[102]}$, and a temperature of $535^{\circ} \mathrm{C}$ for the solution and $180^{\circ} \mathrm{C}$ for aging (T6) seemed to be a good compromise for A356-0.54Sc alloy and was thus employed in experiments, as shown in Figure 13. The UTS, YS, and EL of the A356-0.54Sc alloy during the T6 heat treatment are $331 \mathrm{MPa}, 263 \mathrm{MPa}$, and $12 \%$, respectively, which are $29.8 \%, 94.8 \%$, and $9.1 \%$ higher than those of the original cast alloy.

\section{Design of Sr-modified casting A356 alloys driven by combining CT and ML}

As discussed above, the quantitative relationship of "Composition - Process - Microstructure - Properties" of casting aluminum alloys can be established by combining CT and ML techniques to develop highperformance alloys efficiently. A nice example in the design of Sr-modified casting A356 alloys was reported very recently by the present authors ${ }^{[168,184]}$. First, a reliable thermodynamic database for the Al-rich Al-Si$\mathrm{Mg}$-Sr quaternary system was established, from which the quantitative relationship between the composition and microstructure of the A356-Sr system was constructed. Combining the calculated phase/microstructure data with the measured experimental mechanical properties, the ML technique was applied to the Sr modification of A356 alloys in the framework of computational alloy design. The quintessence is depicted in Figure 14. 

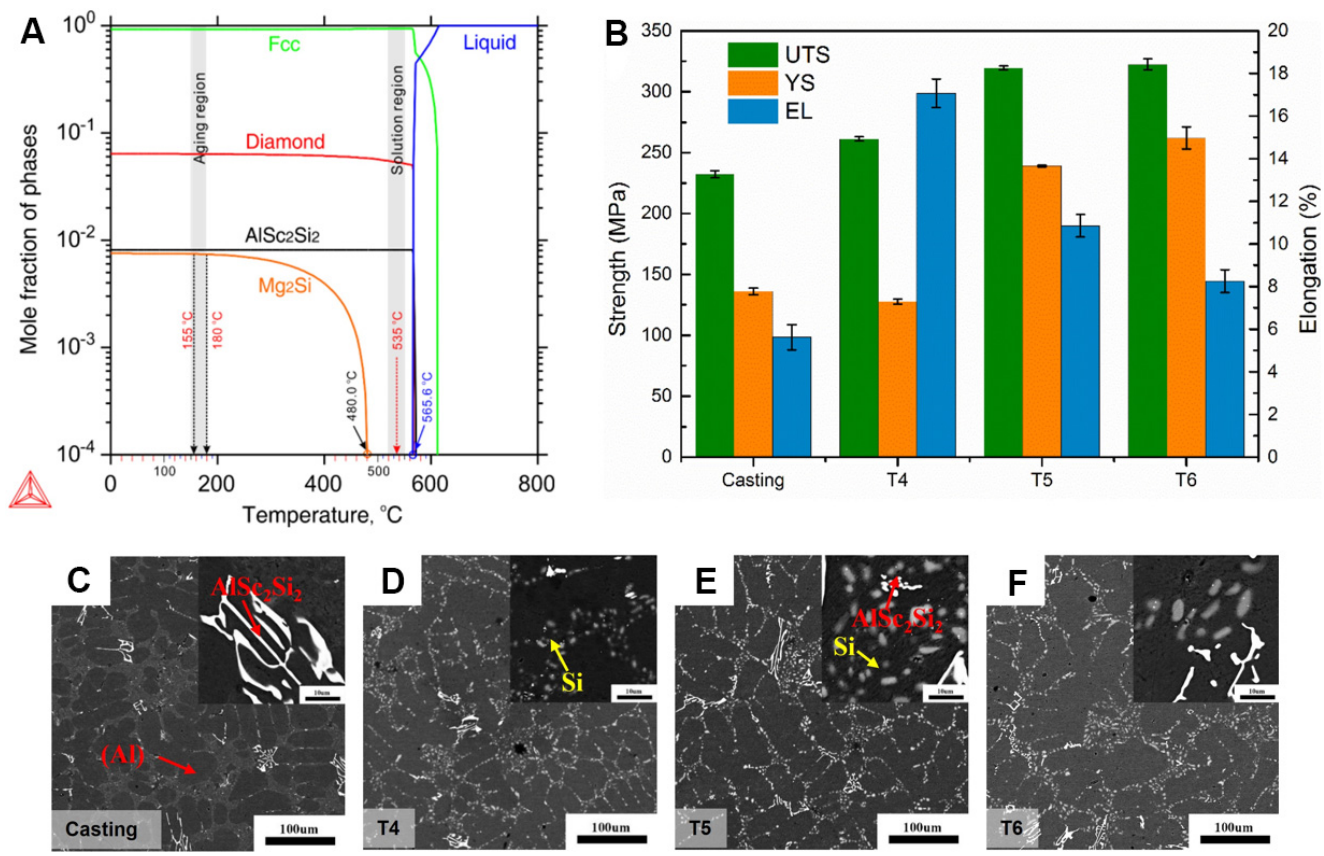

Figure 13. Optimization of solution and aging temperatures of A356-0.54Sc (Al-7.0Si-0.4Mg-0.54Sc, in wt\%) alloy driven by CT approach, and the corresponding experimental verification. (A) Calculated property diagram of A356-0.54Sc alloy; (B) measured mechanical properties of A356-0.54Sc alloys with different treatments; (C-F) backscattered electron images of A356 alloys with different heat treatments. Figure reproduced from Ref. ${ }^{[102]}$ with permission from Elsevier.

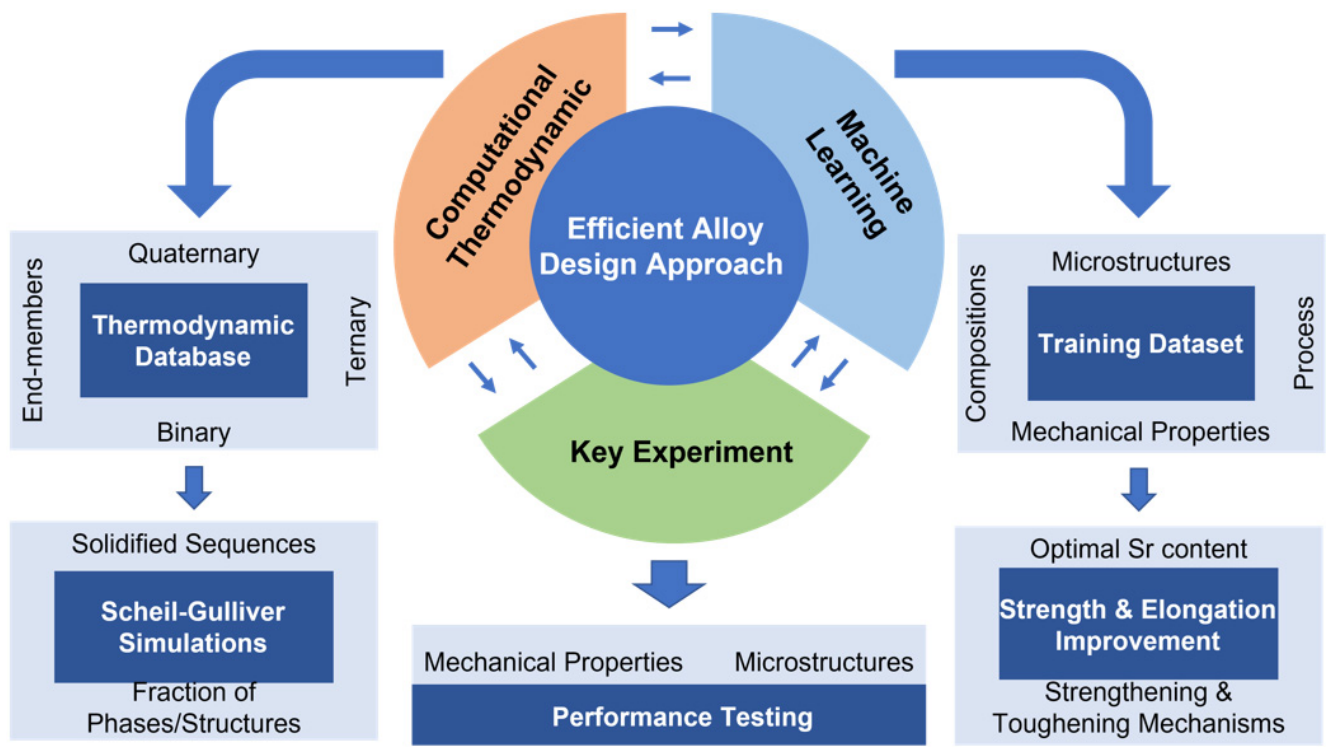

Figure 14. Strategic workflow for the alloy design approach driven by combing computational thermodynamic and machine learning techniques. Figure reproduced from Ref. ${ }^{[168]}$ with permission from Elsevier.

To establish the self-consistent thermodynamic database of the Al-rich Al-Si-Mg-Sr quaternary system, all the thermodynamic parameters of six boundary binaries, i.e., Al-Si, $\mathrm{Al}-\mathrm{Mg}, \mathrm{Al}-\mathrm{Sr}, \mathrm{Mg}-\mathrm{Si}, \mathrm{Mg}-\mathrm{Sr}$, and $\mathrm{Si}-\mathrm{Sr}$ were first unified. Subsequently, the thermodynamic parameters for the Al-Si-Sr and Al-Mg-Sr systems were reassessed using the CALPHAD method based on all critically reviewed experimental phase equilibria and thermodynamic property information ${ }^{[184]}$. Then, the thermodynamic database for the Al-Si-Mg-Sr 
quaternary system was established by combining the four ternary subsystems, and the phase equilibria/thermodynamic properties of the quaternary system were predicted via direct extrapolation from the ternary systems.

To design the optimal amount of Sr in A356 alloys, Yi et al. ${ }^{[168]}$ proposed an efficient approach by combining $\mathrm{CT}$ and ML techniques. As presented in Figure 15. the phase/microstructure fraction in different Srmodified A356 alloys predicted from the Scheil-Gulliver solidification simulations based on the reliable thermodynamic database, combined with the measured mechanical properties of the alloy, were used as the input data in the machine learning model to establish the quantitative relation of "Composition - Process Microstructure - Properties" in Sr-modified A356 alloys, from which two critical points of Sr-modified A356 alloys were predicted. The content of Sr in A356 alloys with the best comprehensive performance was determined to be $0.005 \mathrm{wt} \%$, which was then verified by key experiments.

Furthermore, the strengthening and toughing mechanisms of the Sr-modified A356 alloys were further studied based on the quantitative "Microstructures - Properties" matrix. As displayed in Figure 16, the contribution to the strength in Sr-modified A356 alloys mainly comes from the eutectic structure $(\mathrm{Al})+(\mathrm{Si})$, while the contribution to the elongation is mainly due to primary $\alpha-(\mathrm{Al})$ and soft $\mathrm{Al}_{2} \mathrm{Si}_{2} \mathrm{Sr}$ compounds.

The successful design of Sr-modified Al-Si-Mg casting alloys by combining CT and ML shows that such a combinatorial approach can provide a standard scheme for the efficient and accurate design of cast aluminum alloys.

\section{CONCLUSIONS \& PERSPECTIVES}

This paper comprehensively reviews the state-of-the-art computational alloy design approaches driven by CT and ML techniques as well as their combinations. Successful case studies on the design of different aluminum alloys driven by CT, ML, and their combinations were demonstrated, including common applications, CT-driven design of Sc-additional Al-Si-Mg series casting alloys, and design of Sr-modified A356 alloys driven by combing CT and ML. To sum up, the following three conclusions can be drawn:

(1) The CT approach based on an accurate thermodynamic database in the framework of CALPHAD technique can be used to efficiently predict different factors determining the as-cast microstructure of casting alloys, like the castability, the crack susceptibility index, the growth restriction factor, and so on, which definitely benefits for the common alloy design. The quantitative relation of "Composition - Process Microstructure" can also be established by CT technique for casting aluminum alloys, from which the successful design of Sc-additional Al-Si-Mg series casting alloys was demonstrated, with the aid of the empirical relation of "Microstructure - Properties". Moreover, with the property diagram computed from the CT approach, the optimal solid solution and aging temperatures for Sc-additional Al-Si-Mg series casting alloys were also designed.

(2) The data-driven ML techniques can be used to effectively construct the relation between any two types of variables without knowing their physical connection in advance, and thus widely utilized in the alloy design, as demonstrated in several common applications in aluminum alloys. Moreover, the ML techniques might also be responsible for refining the basic features behind repetitive but expensive operations, especially when the interpolations are needed in high-dimensional spaces. However, a large dataset is typically needed for a reasonable ML prediction. 

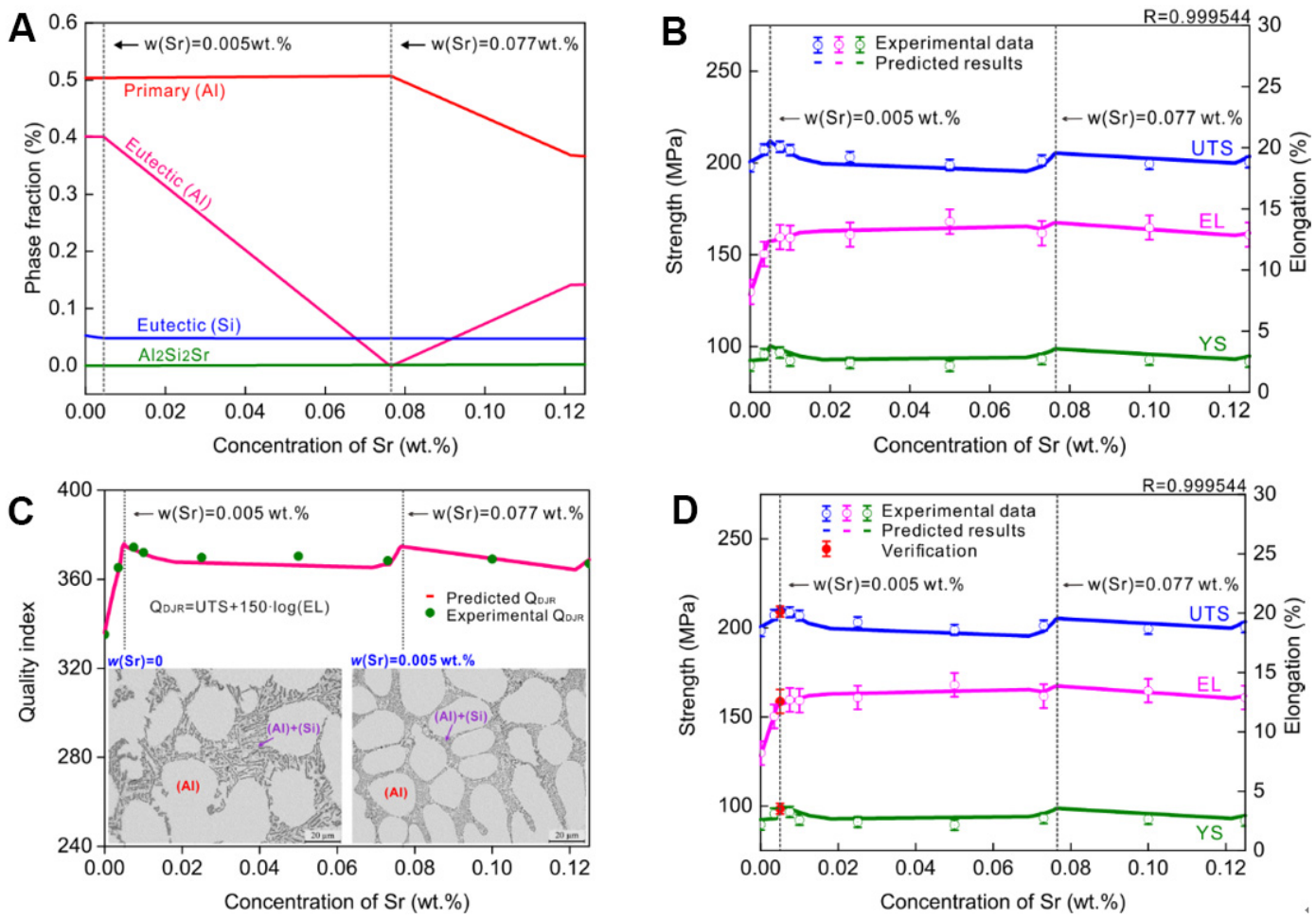

Figure 15. Alloy design of Sr-modified A356 alloys driven by combing computational thermodynamic and machine learning techniques. (A) Fraction of different phases/structures in Sr-modified A356 obtained by CT; (B) measured and training mechanical properties of A356-xSr alloys. (C) Quality index $\left[Q_{D I R}=U T S+150 \cdot \log (E L)\right]$ of Sr-modified A356 alloys computed from the predicted and the experimental data. (D) Experimental verification of the predicted optimal Sr additional content (i.e., 0.005 wt\%) and corresponding best mechanical properties. Figure reproduced from Ref. ${ }^{[168]}$ with permission from Elsevier.

(3) The combination of CT and ML techniques was highly proposed in this review for efficiently constructing the quantitative relation of "Composition - Process - Microstructure - Properties" for the casting aluminum alloys, from which a successful design of Sr-modified A356 alloys was demonstrated even with a small dataset. Moreover, the "Microstructure-Properties" matrix training by ML may further provide a feasible means for understanding the strengthening/toughening mechanisms of casting aluminum alloy. Thus, such a combination of CT and ML is anticipated to boost the concept design of cast aluminum alloys for various industrial applications.

In the pursuance of further advance the field of combing CT and ML techniques for alloy design, the following points are highly recommended to follow up:

The first point that remains under further improvement is to improve the efficiency of alloy design and accelerate the alloy design process. HTCs are time-consuming, and the efficient management of the calculation tasks and the post-processing of calculation results of HTCs are still challenging. Recently, a machine learning accelerated distributed task management system (Malac-Distmas) was developed in our research group to realize the HTCs and storage of various data ${ }^{[185]}$, as shown in Figure 17. The ML technique was also embedded in Malac-Distmas to densify the output data, reducing the amount of calculation, and achieving the acceleration of HTCs. Combining Malac-Distmas with different thermodynamic calculation software, HTCs and storage of the Gibbs energy, phase diagram, Scheil-Gulliver simulation, as well as property diagram were performed, which may accelerate the concept design of casting aluminum alloys. 


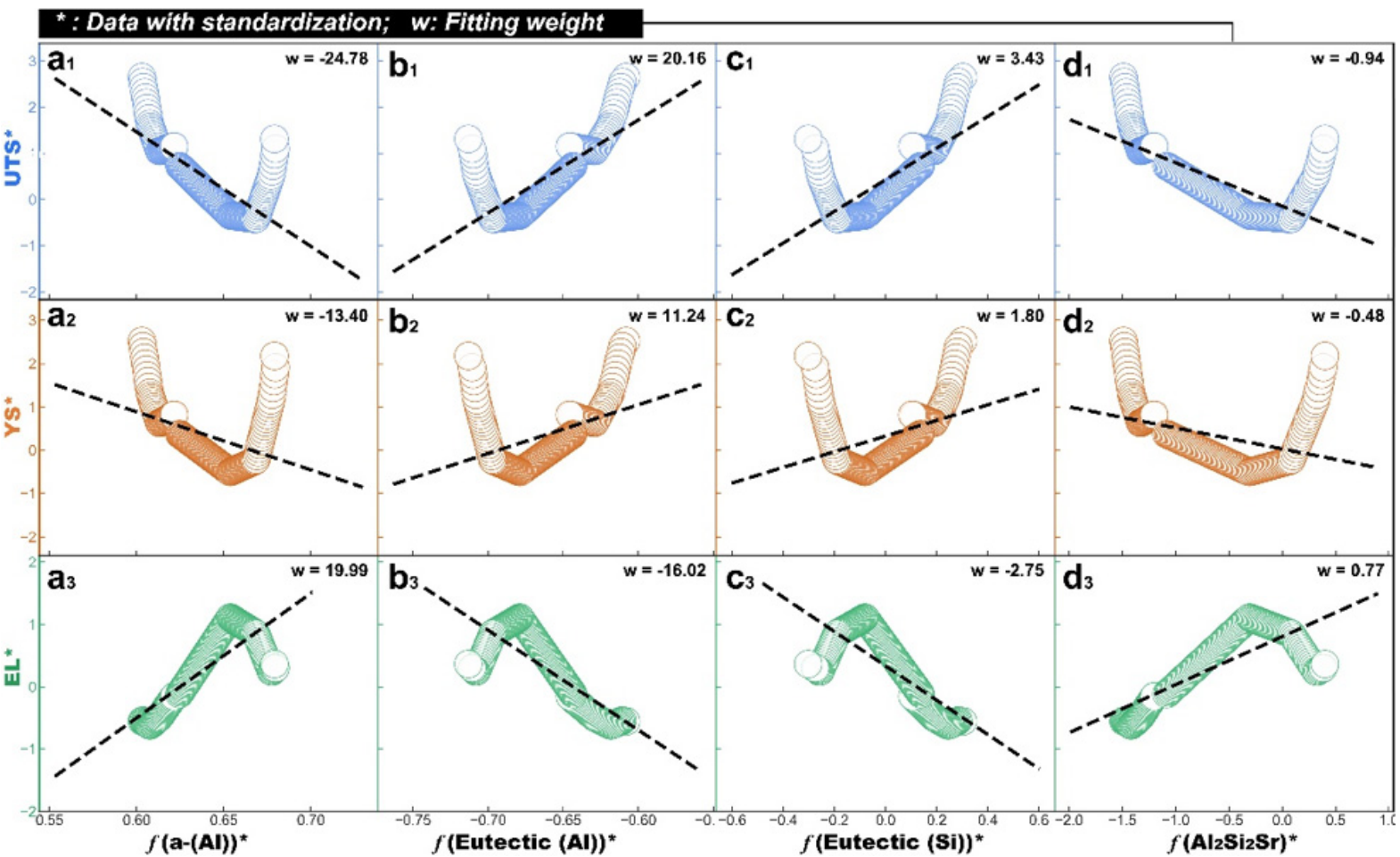

Figure 16. Relations between different mechanical properties and volume fractions of different phases/structures after standardization due to $\mathrm{ML}$ technique. (a) primary $\alpha-(\mathrm{Al})$; (b) eutectic ( $\mathrm{Al}$ ); (c) eutectic ( $\mathrm{Si}$ ); (d) $\mathrm{Al}_{2} \mathrm{Si}_{2} \mathrm{Sr}$. Figure reproduced from Ref. ${ }^{[168]}$ with permission from Elsevier.
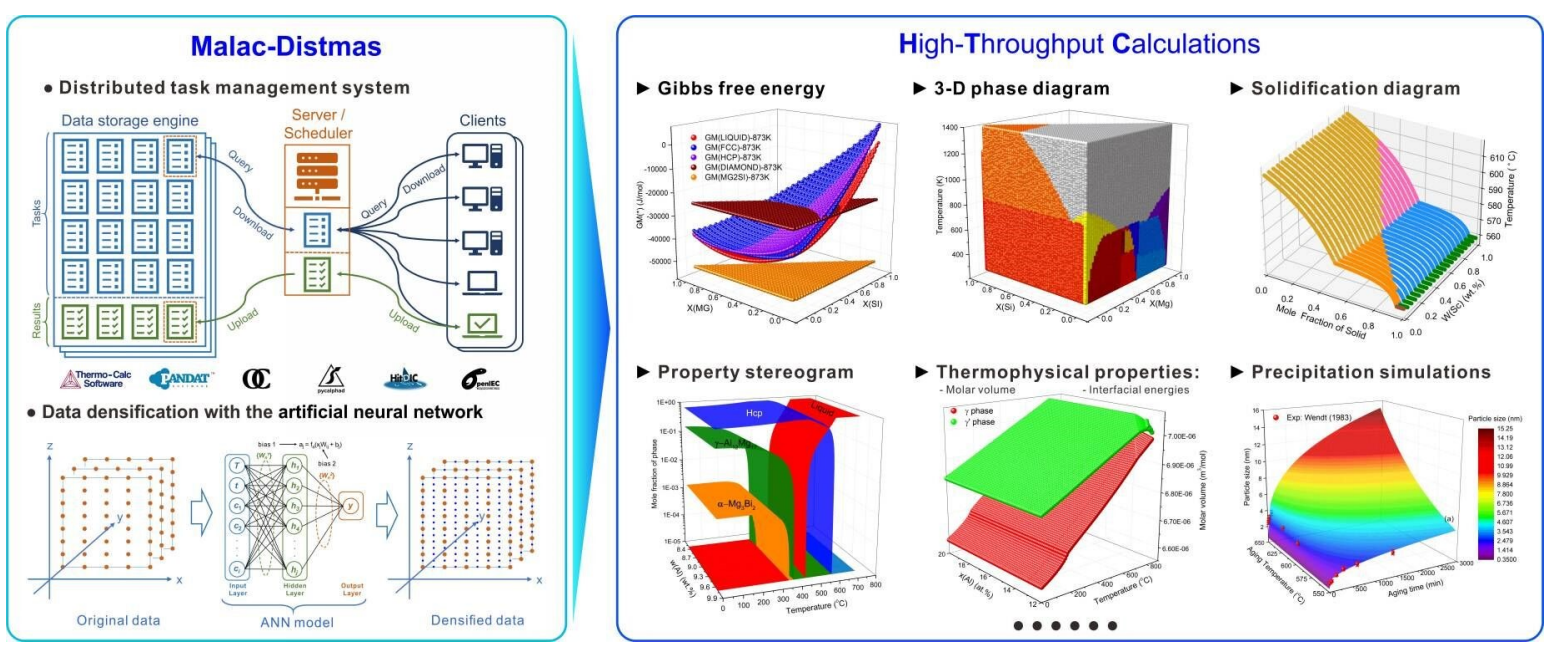

Figure 17. Framework of the Malac-Distmas and its application to high-throughput computational thermodynamics. Figure reproduced from Ref. ${ }^{[185]}$ with permission from Elsevier.

The second point is to extend this combinatorial approach in the design of post-heat treatment mechanisms for casting aluminum alloys. Contrary to the alloy design in the casting process, there are few reports on the design of heat treatment mechanisms by combining computational thermodynamics and machine learning techniques, except for common applications of CT in designing the solution and aging temperatures ${ }^{[102]}$. Very recently, some efforts have been made on the design of heat treatment mechanisms driven by the ML technique in our research group, as indicated in Figure 18. First of all, a suitable ML model should be 
A
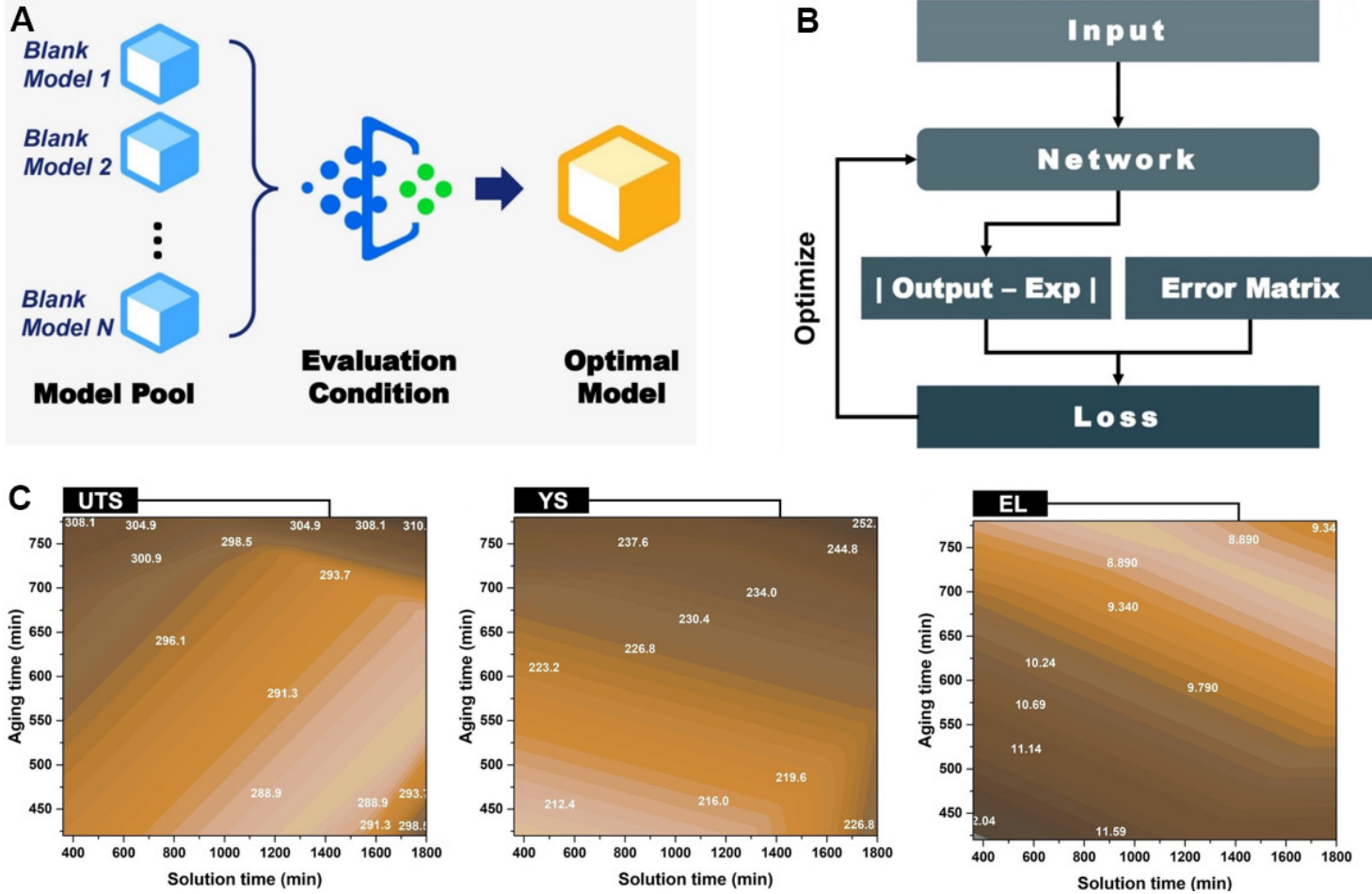

Figure 18. Heat treatment process design of Sc-modified A356 casting alloys driven by $M L$ technique: (A) schematic diagram of the ML model structure; (B) schematic diagram of the model design principle; (C) effects of solution/aging treatment time on UTS, YS, and EL of A356-0.54Sc alloy driven by ML technique.

selected before training. As shown in Figure 18A, an ML model pool containing several blank ML models was established by evaluating and comparing all the ML training results in the ML model pool. The model with the smallest training error value and the most concentrated training data was chosen as the optimal one. Here, the ANN model based on the multilayer perceptron was designed, as shown in Figure 18B, and an error matrix was embedded in the machine learning model to solve the under-fitting and over-fitting problems in the machine learning design process of small datasets. The effect of solution/aging time on the mechanical properties (i.e., UTS, YS, and EL) of A356-0.54Sc cast alloy predicted by the ML method was presented in Figure 18C, according to the relation between the solution/aging time and mechanical properties of casting aluminum alloy. Then based on Figure $18 \mathrm{C}$, one can quickly select the solution/aging time with their required properties while saving energy and reducing emissions. Thus, a combination of CT and ML seems very promising to perform the accurate/efficient design of the post-heat treatment mechanisms of casting aluminum alloys.

The last but not the least point is to extend this method to different manufacturing processes, such as highpressure casting, additive manufacturing, and so on. Temperature and pressure are the two important parameters that affect the solidification behavior of alloys. When the alloy is solidified under high pressure, not only the grain size of the alloy can be effectively reduced, but also the phase structure and composition can be adjusted. As shown in Figure 19A and B, the primary phase of $\mathrm{Al}-20 \mathrm{wt} \% \mathrm{Mg}_{2} \mathrm{Si}$ alloy solidified at 1 bar is $\mathrm{Mg}_{2} \mathrm{Si}$ phase and transforms into $\alpha-\mathrm{Al}$ phase at $3 \mathrm{GPa}^{[22]}$. Moreover, the pressure further promotes the refinement of the eutectic $\mathrm{Mg}_{2} \mathrm{Si}$ phase. Based on the thermodynamic database of the Al-Si-Mg system under pressure recently established in our research group, the solidification curves of $\mathrm{Al}-20 \mathrm{wt} \% \mathrm{Mg}_{2} \mathrm{Si}$ alloy at 1 bar and $3 \mathrm{GPa}$ were simulated and presented in Figure $19 \mathrm{C}$ and D. As can be seen in the figure, the microstructure evolution of $\mathrm{Al}-20 \mathrm{wt} \% \mathrm{Mg}_{2} \mathrm{Si}$ alloy under different pressures can be well simulated by the CT 

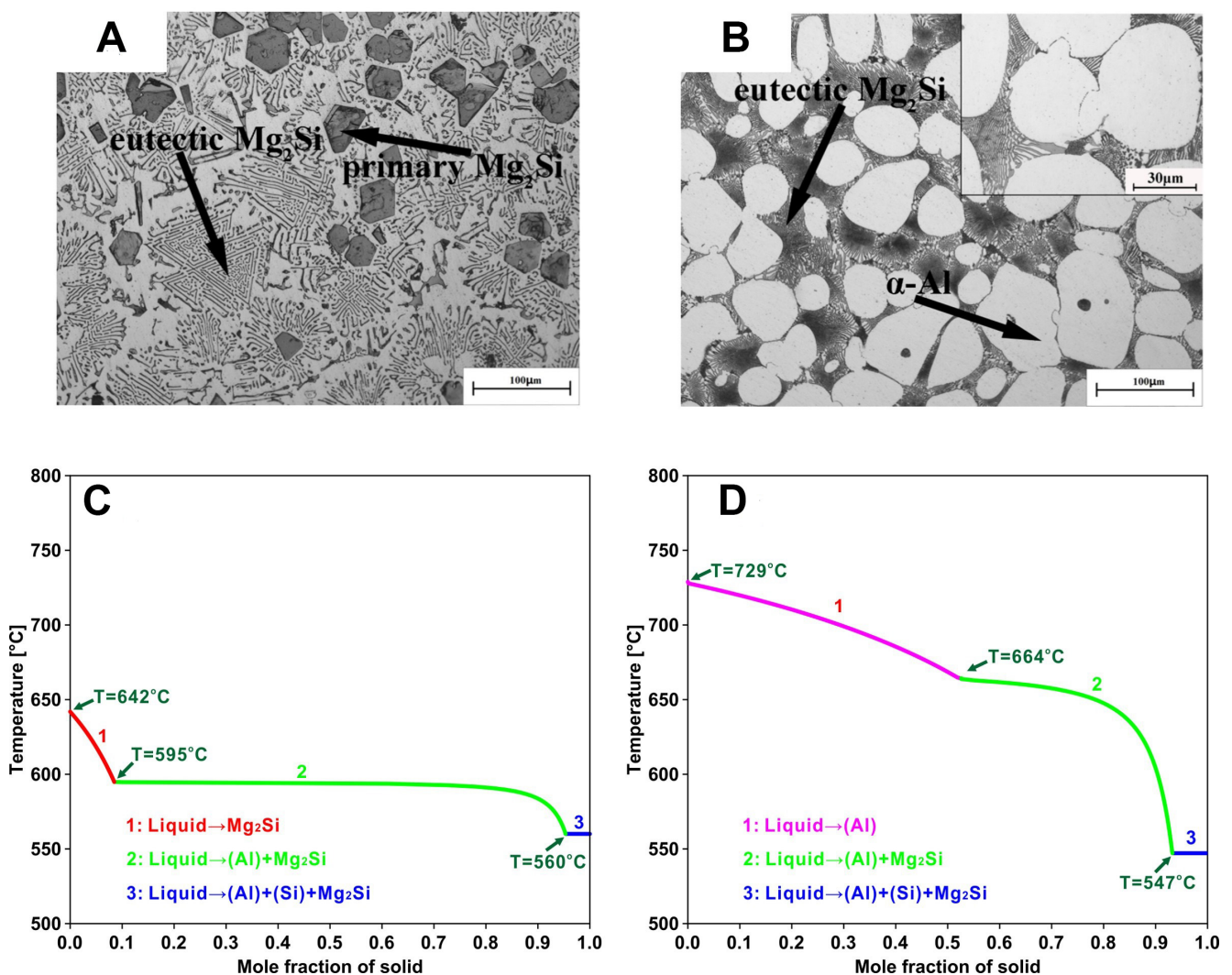

Figure 19. Experimental solidification microstructures and simulated solidification curves of $\mathrm{Al}-2 \mathrm{Owt} \% \mathrm{Mg}_{2} \mathrm{Si}$ alloy under different pressure: (A) solidified microstructure of Al-20wt $\% \mathrm{Mg}_{2} \mathrm{Si}$ alloy at 1 bar ${ }^{[22]}$, (B) solidified microstructure of $\mathrm{Al}-20 \mathrm{wt} \% \mathrm{Mg}_{2} \mathrm{Si}$ alloy at $3 \mathrm{GPa}^{[22]}$, (B) Scheil-Gulliver solidification curve of Al-20wt\% Mg 2 Si alloy at 1 bar, (D) Scheil-Gulliver solidification curve of Al-20wt\% $\mathrm{Mg}_{2} \mathrm{Si}$ alloy at $3 \mathrm{GPa}$. The solidification microstructure were reproduced from Ref. ${ }^{[22]}$ with permission from Elsevier, and the solidification curves were simulated in the present work.

technique. In addition, the phase transition temperature, solidification sequence, and solid fraction of the alloys under pressure can be obtained efficiently by the CT technique. If a combination of CT and ML is feasible in this direction, it will be of great significance to the design of aluminum alloys fabricated via highpressure casting.

Undoubtedly, additive manufacturing technology brings great opportunities for the manufacture of metal structure products, especially those with complex structures. Currently, there is a lack of special aluminum alloy for additive manufacturing. The traditional aluminum alloys used in additive manufacturing have the problem of high cracking tendency and columnar grains formation. Therefore, it is urgent to develop aluminum alloys for additive manufacturing. Recently, Zhang et al ${ }^{[186]}$ designed a crack-free Ti-modified $\mathrm{Al}-\mathrm{Cu}-\mathrm{Mg}$ alloy for selective laser melting alloy with the help of CT technique, as presented in Figure 20. The calculated results indicated that Ti content has little effect on the hot crack susceptibility while having a strong impact on the growth restriction of $\alpha$-Al grains, which was verified by subsequent experiments. It can be seen in Figure $20 \mathrm{C}$ and $\mathrm{D}$ that with the addition of Ti element, the microstructures of $\alpha-\mathrm{Al}$ in $\mathrm{Al}-\mathrm{Cu}-\mathrm{Mg}$ alloys were modified from coarse columnar grains into fine equiaxed grains. It is highly expected that a combination of CT and ML may realize the accurate and efficient computational alloy design for additive manufacturing. 

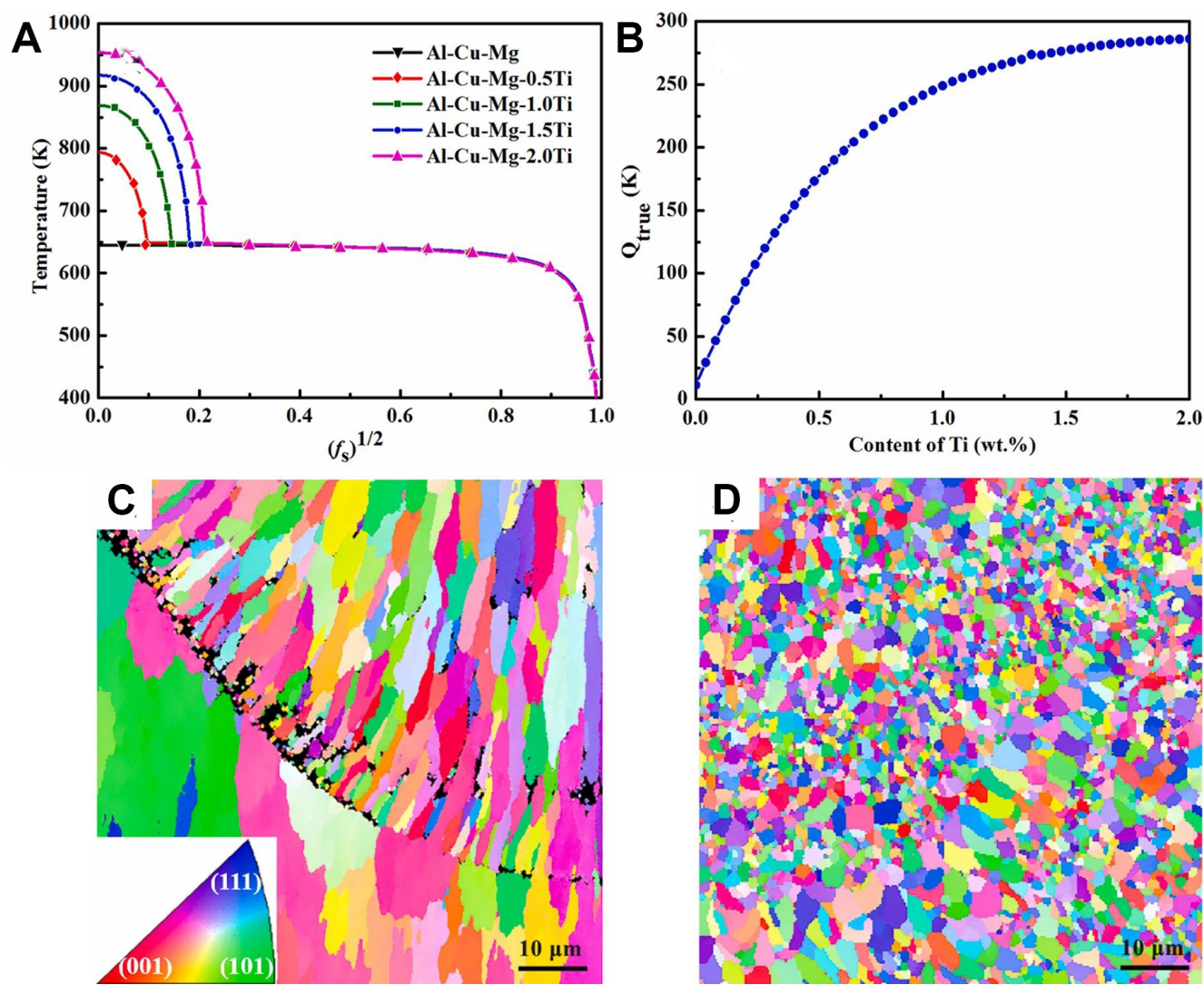

Figure 20. CT-driven design and experimental verification of additive manufactured Ti-modified Al-Cu-Mg alloys: (A) T vs. $(f s)^{1 / 2}$ curves of $\mathrm{Al}-\mathrm{Cu}-\mathrm{Mg}-x \mathrm{Ti}$ alloys with Ti contents ranging from $\mathrm{O}$ to $2 \mathrm{wt} \%$; (B) calculated $\mathrm{Q}_{\text {true }}$ values in Ti/Al-Cu-Mg alloys for constrained $\mathrm{L} \rightarrow \alpha$-Al solidification with Ti contents ranging from 0 to $2 \mathrm{wt} \%$; EBSD orientation maps from side view of SLM-fabricated (C) Al-Cu-Mg and (D) Ti-modified Al-Cu-Mg alloys. Figure reproduced from Ref. ${ }^{[186]}$ with permission from Elsevier.

\section{DECLARATIONS}

\section{Acknowledgments}

The authors would like to thank Mr. Jing Zhong, Mr. Qiang Tang, Mr. Shaoji Zhang, Miss Jiali Zhang, and Miss Lingyang Zeng from State Key Laboratory of Powder Metallurgy, Central South University, for kindly helping with the preparation of the figures.

\section{Authors' contributions}

Made substantial contributions to the conception and design of the study and performed data analysis and interpretation: Yi W, Liu G, Zhang L

Performed data acquisition, as well as providing administrative, technical, and material support: Gao J, Zhang L

\section{Availability of data and materials}

Not applicable.

\section{Financial support and sponsorship}

This work was supported by the Science and Technology Program of Guangxi province, China (Grant No. AB21220028), the Youth Talent Project of Innovation-driven Plan at Central South University, China (Grant No. 2282019SYLB026), the Lvyangjinfeng Talent program of Yangzhou, China. Wang Yi acknowledges the Fundamental Research Funds for the Central Universities of Central South University 
(Grant No. 2021zzts0094).

\section{Conflicts of interest}

All authors declared that there are no conflicts of interest.

\section{Ethical approval and consent to participate}

Not applicable.

\section{Consent for publication}

Not applicable.

\section{Copyright}

(c) The Author(s) 2021.

\section{REFERENCES}

1. Kaufman JG, Rooy EL. Aluminum alloy castings: properties, processes, and applications. Asm International; 2004. DOI

2. Hirsch J. Recent development in aluminium for automotive applications. Trans Nonferrous Met Soc China 2014;24:1995-2002. DOI

3. Kelly JC, Sullivan JL, Burnham A, Elgowainy A. Impacts of vehicle weight reduction via material substitution on life-cycle greenhouse gas emissions. Environ Sci Technol 2015;49:12535-42. DOI PubMed

4. Rams J, Torres B. Casting aluminum alloys. Encyclopedia of materials: metals and alloys. Elsevier; 2022. p. 123-31.

5. Zolotorevsky VS, Belov NA, Glazoff M V. Casting Aluminum Alloys. Elsevier; 2007.

6. Javidani M, Larouche D. Application of cast Al-Si alloys in internal combustion engine components. Int Mater Rev 2014;59:132-58. DOI

7. Zamani M, Seifeddine S. Determination of optimum Sr level for eutectic Si modification in Al-Si cast alloys using thermal analysis and tensile properties. Inter Metalcast 2016;10:457-65. DOI

8. Fernández-lópez P, Alves S, López-ortega A, San José-lombera J, Bayón R. High performance tribological coatings on a secondary cast Al-Si alloy generated by Plasma Electrolytic Oxidation. Ceram Int 2021;47:31238-50. DOI

9. Jie J, Zou C, Wang H, Li B, Wei Z. Enhancement of mechanical properties of Al-Mg alloy with a high Mg content solidified under high pressures. Scr Mater 2011;64:588-91. DOI

10. Jie J, Zou C, Brosh E, Wang H, Wei Z, Li T. Microstructure and mechanical properties of an Al-Mg alloy solidified under high pressures. J Alloys Compd 2013;578:394-404. DOI

11. Jie J, Zou C, Wang H, Wei Z, Li T. Thermal stability of Al-Mg alloys after solidification under high pressures. J Alloys Compd 2014;584:507-13. DOI

12. Yang B, Wang Y, Gao M, Guan R. The response of mechanical property to the microstructure variation of an Al-Mg alloy by adding tin element. Mater Sci Eng A 2021;825:141901. DOI

13. Zhao Q, Zhang Q, Zhang W, Qiu F, Jiang Q. Improved ductility and toughness of an Al-Cu casting alloy by changing the geometrical morphology of dendritic grains. Mater Lett 2018;214:276-9. DOI

14. Li Q, Zhang Y, Zhang X, et al. Microstructure evolution and nano-phases strengthening of Al-5\%Cu alloy by adding trace AlSiTiCrNiCu high entropy alloy. Mater Charact 2021;175:111100. DOI

15. Shin S, Lim K, Park I. Characteristics and microstructure of newly designed Al-Zn-based alloys for the die-casting process. $J$ Alloys Compd 2016;671:517-26. DOI

16. Mishra RR, Sharma AK. Structure-property correlation in Al-Zn-Mg alloy cast developed through in-situ microwave casting. Mater Sci Eng A 2017;688:532-44. DOI

17. Liu C, Garner A, Zhao H, et al. CALPHAD-informed phase-field modeling of grain boundary microchemistry and precipitation in Al-Zn-Mg-Cu alloys. Acta Mater 2021;214:116966. DOI

18. Lu K. Materials science. The future of metals. Science 2010;328:319-20. DOI PubMed

19. Tang Y, Li Y, Zhao W, Roslyakova I, Zhang L. Thermodynamic descriptions of quaternary Mg-Al-Zn-Bi system supported by experiments and their application in descriptions of solidification behavior in Bi-additional AZ casting alloys. $J$ Magnes Alloy 2020;8:1238-52. DOI

20. Wang T, Yang L, Tang Z, et al. Effect of aging treatment on microstructure, mechanical and corrosion properties of 7055 aluminum alloy prepared using powder by-product. Mater Sci Eng A 2021;822:141606. DOI

21. Lavernia EJ, Srivatsan TS. The rapid solidification processing of materials: science, principles, technology, advances, and applications. J Mater Sci 2010;45:287-325. DOI

22. Tong X, Zhang D, Wang $\mathrm{K}$, et al. Microstructure and mechanical properties of high-pressure-assisted solidification of in situ Al-Mg Si composites. Mater Sci Eng A 2018;733:9-15. DOI

23. Qi M, Kang Y, Li J, et al. Microstructures refinement and mechanical properties enhancement of aluminum and magnesium alloys by combining distributary-confluence channel process for semisolid slurry preparation with high pressure die-casting. J Mater Process 
Technol 2020;285:116800. DOI

24. Yang H, Zhang Y, Wang J, Liu Z, Liu C, Ji S. Additive manufacturing of a high strength Al- $5 \mathrm{Mg}_{2} \mathrm{Si}-2 \mathrm{Mg}$ alloy: Microstructure and mechanical properties. J Mater Sci Technol 2021;91:215-23. DOI

25. Weiss D. Advances in the Sand Casting of Aluminium Alloys. Fundamentals of Aluminium Metallurgy. Elsevier; 2018. p. 159-71. DOI

26. Xiao G, Jiang J, Liu Y, Wang Y, Guo B. Recrystallization and microstructure evolution of hot extruded 7075 aluminum alloy during semi-solid isothermal treatment. Mater Charact 2019;156:109874. DOI

27. Lu L, Nogita K, Dahle A. Combining Sr and Na additions in hypoeutectic Al-Si foundry alloys. Mater Sci Eng A 2005;399:244-53. DOI

28. Ganesh MRS, Reghunath N, J. levin M, Prasad A, Doondi S, Shankar KV. Strontium in Al-Si-Mg alloy: a review. Met Mater Int 2021. DOI

29. Wu Y, Zhang J, Liao H, Li G, Wu Y. Development of high performance near eutectic Al-Si-Mg alloy profile by micro alloying with Ti. J Alloys Compd 2016;660:141-7. DOI

30. Li Y, Hu B, Liu B, et al. Insight into Si poisoning on grain refinement of Al-Si/Al-5Ti-B system. Acta Mater 2020;187:51-65. DOI

31. Zhao C, Li Y, Xu J, et al. Enhanced grain refinement of Al-Si alloys by novel Al-V-B refiners. J Mater Sci Technol 2021;94:104-12. DOI

32. Li Y, Jiang Y, Liu B, Luo Q, Hu B, Li Q. Understanding grain refining and anti Si-poisoning effect in Al-10Si/Al-5Nb-B system. J Mater Sci Technol 2021;65:190-201. DOI

33. Liu G, Blake P, Ji S. Effect of Zr on the high cycle fatigue and mechanical properties of Al-Si-Cu-Mg alloys at elevated temperatures. J Alloys Compd 2019;809:151795. DOI

34. Lu Z, Li X, Zhang L. Thermodynamic description of Al-Si-Mg-Ce quaternary system in Al-rich corner and its experimental validation. J Phase Equilib Diffus 2018;39:57-67. DOI

35. Li JH, Ludwig TH, Oberdorfer B, Schumacher P. Solidification behaviour of Al-Si based alloys with controlled additions of Eu and P. Int J Cast Met Res 2018;31:319-31. DOI

36. Zhang J, Gao Y, Yang C, et al. Microalloying Al alloys with Sc: a review. Rare Met 2020;39:636-50. DOI

37. Zhang X, Huang L, Zhang B, et al. Enhanced strength and ductility of A356 alloy due to composite effect of near-rapid solidification and thermo-mechanical treatment. Mater Sci Eng A 2019;753:168-78. DOI

38. Zhang X, Huang LK, Zhang B, Chen YZ, Liu F. Microstructural evolution and strengthening mechanism of an Al-Si-Mg alloy processed by high-pressure torsion with different heat treatments. Mater Sci Eng A 2020;794:139932. DOI

39. Zhou J, Zhong J, Chen L, et al. Phase equilibria, thermodynamics and microstructure simulation of metastable spinodal decomposition in c-Ti1-xAlxN coatings. Calphad 2017;56:92-101. DOI

40. Fujinaga T, Watanabe Y, Shibuta Y. Nucleation dynamics in Al solidification with Al-Ti refiners by molecular dynamics simulation. Comput Mater Sci 2020;182:109763. DOI

41. Tang Y, Du Y, Zhang L, Yuan X, Kaptay G. Thermodynamic description of the Al-Mg-Si system using a new formulation for the temperature dependence of the excess Gibbs energy. Thermochim Acta 2012;527:131-42. DOI

42. Lu Z, Zhang L. Thermal stability and crystal structure of high-temperature compound Al13CeMg6. Intermetallics 2017;88:73-6. DOI

43. Yang S, Zhong J, Wang J, Zhang L, Kaptay G. OpenIEC: an open-source code for interfacial energy calculation in alloys. J Mater Sci 2019;54:10297-311. DOI

44. Zhong J, Chen W, Zhang L. HitDIC: A free-accessible code for high-throughput determination of interdiffusion coefficients in single solution phase. Calphad 2018;60:177-90. DOI

45. Wu X, Zhong J, Zhang L. A general approach to quantify the uncertainty of interdiffusion coefficients in binary, ternary and multicomponent systems evaluated using Matano-based methods. Acta Mater 2020;188:665-76. DOI

46. Ma S, Xing F, Deng C, Zhang L. A novel analytical approach to describe the simultaneous diffusional growth of multilayer stoichiometric compounds in binary reactive diffusion couples. Scr Mater 2021;191:111-5. DOI

47. Ma S, Xing F, Ta N, Zhang L. Kinetic modeling of high-temperature oxidation of pure Mg. J Magnes Alloy 2020;8:819-31. DOI

48. Zhong J, Chen L, Zhang L. High-throughput determination of high-quality interdiffusion coefficients in metallic solids: a review. $J$ Mater Sci 2020:1-36. DOI PubMed PMC

49. Zhong J, Zhang L, Wu X, Chen L, Deng C. A novel computational framework for establishment of atomic mobility database directly from composition profiles and its uncertainty quantification. J Mater Sci Technol 2020;48:163-74. DOI

50. Zhong J, Chen L, Zhang L. Automation of diffusion database development in multicomponent alloys from large number of experimental composition profiles. npj Comput Mater 2021;7:35. DOI

51. Tang Q, Ma S, Xing F, Zhang L. Anisotropic atomic mobilities of hep $\operatorname{Zr}(\mathrm{O})$ solid solution and their application in description of early-stage oxidation process of pure Zr. Corros Sci 2021;186:109445. DOI

52. Wei M, Tang Y, Zhang L, Sun W, Du Y. Phase-field simulation of microstructure evolution in industrial A2214 alloy during solidification. Metall Mater Trans A 2015;46:3182-91. DOI

53. Zhang L, Stratmann M, Du Y, Sundman B, Steinbach I. Incorporating the CALPHAD sublattice approach of ordering into the phasefield model with finite interface dissipation. Acta Mater 2015;88:156-69. DOI

54. Wang K, Wei M, Zhang L, Du Y. Morphologies of primary silicon in hypereutectic Al-Si alloys: phase-field simulation supported by key experiments. Metall Mater Trans A 2016;47:1510-6. DOI

55. Gao J, Wei M, Zhang L, Du Y, Liu Z, Huang B. Effect of different initial structures on the simulation of microstructure evolution 
during normal grain growth via phase-field modeling. Metall Mater Trans A 2018;49:6442-56. DOI

56. Wang K, Zhang L. Quantitative phase-field simulation of the entire solidification process in one hypereutectic Al-Si alloy considering the effect of latent heat. Prog Nat Sci Mater Int 2021;31:428-33. DOI

57. Meredig B, Agrawal A, Kirklin S, et al. Combinatorial screening for new materials in unconstrained composition space with machine learning. Phys Rev B 2014;89:094104. DOI

58. Wen C, Zhang Y, Wang C, et al. Machine learning assisted design of high entropy alloys with desired property. Acta Mater 2019;170:109-17. DOI

59. Yang S, Lu J, Xing F, Zhang L, Zhong Y. Revisit the VEC rule in high entropy alloys (HEAs) with high-throughput CALPHAD approach and its applications for material design-A case study with Al-Co-Cr-Fe-Ni system. Acta Mater 2020;192:11-9. DOI

60. Ruan J, Xu W, Yang T, et al. Accelerated design of novel W-free high-strength Co-base superalloys with extremely wide $\gamma / \gamma^{\prime}$ region by machine learning and CALPHAD methods. Acta Mater 2020;186:425-33. DOI

61. Tiryakioğlu M, Campbell J, Alexopoulos ND. Quality indices for aluminum alloy castings: a critical review. Metall Mater Trans $B$ 2009;40:802-11. DOI

62. Tiryakioglu M, Campbell J, Amer Foundry S. Quality index for aluminum alloy castings. Trans Am Foundry Soc Vol 2013;121:21721.

63. Özdeş H, Tiryakioğlu M. On the relationship between structural quality index and fatigue life distributions in aluminum aerospace castings. Metals 2016;6:81. DOI

64. Liu ZK, Chen LQ, Raghavan P, et al. An integrated framework for multi-scale materials simulation and design. J Computer-Aided Mater Des 2004;11:183-99. DOI

65. Chen H, Chen Q, Engström A. Development and applications of the TCAL aluminum alloy database. Calphad 2018;62:154-71. DOI

66. Deng L, Li X. Machine learning paradigms for speech recognition: an overview. IEEE Trans Audio Speech Lang Process 2013;21:1060-89. DOI

67. Agrawal A, Choudhary A. Perspective: materials informatics and big data: Realization of the "fourth paradigm" of science in materials science. APL Mater 2016;4:053208. DOI

68. Xu X, Wang L, Zhu G, Zeng X. Predicting tensile properties of AZ31 magnesium alloys by machine learning. JOM 2020;72:393542. DOI

69. Liu Y, Wang L, Zhang H, et al. Accelerated development of high-strength magnesium alloys by machine learning. Metall Mater Trans A 2021;52:943-54. DOI

70. Liu Z. Computational thermodynamics and its applications. Acta Mater 2020;200:745-92. DOI

71. Olson GB. Computational design of hierarchically structured materials. Science 1997;277:1237-42. DOI

72. Olson G, Kuehmann C. Materials genomics: from CALPHAD to flight. Scripta Materialia 2014;70:25-30. DOI

73. Sundman B, Lukas HL, Fries SG. Computational thermodynamics: the Calphad method. New York: Cambridge university press; 2007. DOI

74. Lu X, Wang Z, Cui Y, Jin Z. Computational thermodynamics, computational kinetics, and materials design. Chin Sci Bull 2014;59:1662-71. DOI

75. Liu ZK, Wang Y. Appendix A: YPHON. Computational thermodynamics of materials. Cambridge: Cambridge University Press; 2016. p. 221-30. DOI

76. Du Y, Liu S, Zhang L, et al. An overview on phase equilibria and thermodynamic modeling in multicomponent Al alloys: focusing on the Al-Cu-Fe-Mg-Mn-Ni-Si-Zn system. Calphad 2011;35:427-45. DOI

77. Xu G, Zhang L, Liu L, et al. Thermodynamic database of multi-component Mg alloys and its application to solidification and heat treatment. J Magnes Alloy 2016;4:249-64. DOI

78. Shi R, Luo AA. Applications of CALPHAD modeling and databases in advanced lightweight metallic materials. Calphad 2018;62:117. DOI

79. Chen H, Mao H, Chen Q. Database development and Calphad calculations for high entropy alloys: challenges, strategies, and tips. Mater Chem Phys 2018;210:279-90. DOI

80. Luo Q, Guo Y, Liu B, et al. Thermodynamics and kinetics of phase transformation in rare earth-magnesium alloys: a critical review. $J$ Mater Sci Technol 2020;44:171-90. DOI

81. Tang Y, Zhang L, Du Y. Diffusivities in liquid and fec Al-Mg-Si alloys and their application to the simulation of solidification and dissolution processes. Calphad 2015;49:58-66. DOI

82. Schmid-fetzer R, Zhang F. The light alloy Calphad databases PanAl and PanMg. Calphad 2018;61:246-63. DOI

83. Kairy S, Rouxel B, Dumbre J, et al. Simultaneous improvement in corrosion resistance and hardness of a model 2xxx series Al-Cu alloy with the microstructural variation caused by Sc and Zr additions. Corros Sci 2019;158:108095. DOI

84. Zhang C, Miao J, Chen S, Zhang F, Luo AA. CALPHAD-based modeling and experimental validation of microstructural evolution and microsegregation in magnesium alloys during solidification. $J$ Phase Equilib Diffus 2019;40:495-507. DOI

85. Zhang F, Zhang C, Liang S, Lv DC, Chen SL, Cao WS. Simulation of the composition and cooling rate effects on the solidification path of casting aluminum alloys. J Phase Equilib Diffus 2020;41:793-803. DOI

86. Liu S, Wang X, Pan Q, et al. Investigation of microstructure evolution and quench sensitivity of Al-Mg-Si-Mn-Cr alloy during isothermal treatment. $J$ Alloys Compd 2020;826:154144. DOI

87. Kou S. A criterion for cracking during solidification. Acta Mater 2015;88:366-74. DOI

88. Kou S. A simple index for predicting the susceptibility to solidification cracking. Weld Res 2015;94:374-88. DOI

89. Liu J, Kou S. Susceptibility of ternary aluminum alloys to cracking during solidification. Acta Mater 2017;125:513-23. DOI 
90. Soysal T, Kou S. A simple test for assessing solidification cracking susceptibility and checking validity of susceptibility prediction. Acta Mater 2018;143:181-97. DOI

91. Easton M, Stjohn D. A model of grain refinement incorporating alloy constitution and potency of heterogeneous nucleant particles. Acta Mater 2001;49:1867-78. DOI

92. Quested T, Dinsdale A, Greer A. Thermodynamic modelling of growth-restriction effects in aluminium alloys. Acta Mater 2005;53:1323-34. DOI

93. Joshi U, Hari Babu N. The grain refinement potency of bismuth in magnesium. J Alloys Compd 2017;695:971-5. DOI

94. Farkoosh A, Javidani M, Hoseini M, Larouche D, Pekguleryuz M. Phase formation in as-solidified and heat-treated Al-Si-Cu-Mg-Ni alloys: Thermodynamic assessment and experimental investigation for alloy design. J Alloys Compd 2013;551:596-606. DOI

95. Lu Z, Zhang L. Thermodynamic description of the quaternary Al-Si-Mg-Sc system and its application to the design of novel Scadditional A356 alloys. Mater Des 2017;116:427-37. DOI

96. Wei C, Guangxin W, Jieyu Z. Design and properties of Al-10Si-xZn-yMg alloy for hot dip coating. Surf Coatings Technol 2021;416:127134. DOI

97. Zhu X, Liu F, Wang S, Ji S. The development of low-temperature heat-treatable high-pressure die-cast Al-Mg-Fe-Mn alloys with Zn. $J$ Mater Sci 2021;56:11083-97. DOI

98. Nakashima PN, Smith AE, Etheridge J, Muddle BC. The bonding electron density in aluminum. Science 2011;331:1583-6. DOI PubMed

99. Wang Y, Wang WY, Chen LQ, Liu ZK. Bonding charge density from atomic perturbations. J Comput Chem 2015;36:1008-14. DOI PubMed

100. Wang WY, Shang SL, Wang Y, et al. Solid-solution hardening in Mg-Gd-TM (TM = Ag, Zn, and Zr) alloys: an integrated density functional theory and electron work function study. JOM 2015;67:2433-41. DOI

101. Wang WY, Shang SL, Wang Y, et al. Lattice distortion induced anomalous ferromagnetism and electronic structure in FCC Fe and Fe-TM (TM = Cr, Ni, Ta and Zr) alloys. Mater Chem Phys 2015;162:748-56. DOI

102. Liu G, Gao J, Che C, Lu Z, Yi W, Zhang L. Optimization of casting means and heat treatment routines for improving mechanical and corrosion resistance properties of A356-0.54Sc casting alloy. Mater Today Commun 2020;24:101227. DOI

103. Xie T, Shi H, Wang H, Luo Q, Li Q, Chou K. Thermodynamic prediction of thermal diffusivity and thermal conductivity in Mg-ZnLa/Ce system. J Mater Sci Technol 2022;97:147-55. DOI

104. Liu J, Kou S. Crack susceptibility of binary aluminum alloys during solidification. Acta Mater 2016;110:84-94. DOI

105. Zhang F, Liang S, Zhang C, et al. Prediction of cracking susceptibility of commercial aluminum alloys during solidification. Metals 2021;11:1479. DOI

106. Kou S. Predicting susceptibility to solidification cracking and liquation cracking by CALPHAD. Metals 2021;11:1442. DOI

107. Liu J, Zeng P, Kou S. Solidification cracking susceptibility of quaternary aluminium alloys. Sci Technol Weld Join 2021;26:244-57. DOI

108. Deng C, Xu B, Wu P, Li Q. Stability of the $\mathrm{Al}_{\mathrm{TiB}}$ interface and doping effects of Mg/Si. Appl Surf Sci 2017;425:639-45. DOI

109. Chen Z, Kang H, Fan G, et al. Grain refinement of hypoeutectic Al-Si alloys with B. Acta Mater 2016;120:168-78. DOI

110. Li Y, Hu B, Gu Q, Liu B, Li Q. Achievement in grain-refining hypoeutectic Al-Si alloys with Nb. Scr Mater 2019;160:75-80. DOI

111. Qian M, Cao P, Easton M, Mcdonald S, Stjohn D. An analytical model for constitutional supercooling-driven grain formation and grain size prediction. Acta Mater 2010;58:3262-70. DOI

112. Kozlov A, Schmid-fetzer R. Growth restriction factor in Al-Si-Mg-Cu alloys. IOP Conf Ser:Mater Sci Eng 2012;27:012001. DOI

113. Schmid-fetzer R, Kozlov A. Thermodynamic aspects of grain growth restriction in multicomponent alloy solidification. Acta Mater 2011;59:6133-44. DOI

114. Stjohn DH, Prasad A, Easton MA, Qian M. The contribution of constitutional supercooling to nucleation and grain formation. Metall Mater Trans A 2015;46:4868-85. DOI

115. Easton M, Qian M, Prasad A, Stjohn D. Recent advances in grain refinement of light metals and alloys. Curr Opin Solid State Mater Sci 2016;20:13-24. DOI

116. Johnsson M. Influence of Si and Fe on the grain refinement of aluminium. Int J Mater Res 1994;85:781-5. DOI

117. Chai G, Bäackerud L, Arnberg L. Relation between grain size and coherency parameters in aluminium alloys. Mater Sci Technol 2013;11:1099-103. DOI

118. Men H, Fan Z. Effects of solute content on grain refinement in an isothermal melt. Acta Mater 2011;59:2704-12. DOI

119. Scheil E. Bemerkungen zur Schichtkristallbildung. Int J Mater Res 1942;34:70-2. DOI

120. Pelton AD, Eriksson G, Bale CW. Scheil-Gulliver constituent diagrams. Metall Mater Trans A 2017;48:3113-29. DOI PubMed

121. Darling K, Roberts A, Armstrong L, et al. Influence of Mn solute content on grain size reduction and improved strength in mechanically alloyed Al-Mn alloys. Mater Sci Eng A 2014;589:57-65. DOI

122. Yu Q, Shan ZW, Li J, et al. Strong crystal size effect on deformation twinning. Nature 2010;463:335-8. DOI PubMed

123. Hattrick-simpers JR, Gregoire JM, Kusne AG. Perspective: composition-structure-property mapping in high-throughput experiments: turning data into knowledge. APL Mater 2016;4:053211. DOI

124. Garay-tapia A, Romero AH, Trapaga G, Arróyave R. First-principles investigation of the Al-Si-Sr ternary system: ground state determination and mechanical properties. Intermetallics 2012;21:31-44. DOI

125. Li C, Zeng S, Chen Z, Cheng N, Chen T. First-principles calculations of elastic and thermodynamic properties of the four main intermetallic phases in Al-Zn-Mg-Cu alloys. Comput Mater Sci 2014;93:210-20. DOI

126. Huang Z, Zhao Y, Hou H, Han P. Electronic structural, elastic properties and thermodynamics of Mg17Al12, Mg2Si and A12Y 
phases from first-principles calculations. Phys B Condens Matter 2012;407:1075-81. DOI

127. Chen D, Chen Z, Wu Y, Wang M, Ma N, Wang H. First-principles investigation of mechanical, electronic and optical properties of Al3Sc intermetallic compound under pressure. Comput Mater Sci 2014;91:165-72. DOI

128. Zheng B, Zhao L, Hu X, Dong S, Li H. First-principles studies of Mg17Al12, Mg2Al3, Mg2Sn, MgZn2, Mg2Ni and Al3Ni phases. Phys B Condens Matter 2019;560:255-60. DOI

129. Dodd SP, Cankurtaran M, Saunders GA, James B. Ultrasonic determination of the temperature and hydrostatic pressure dependences of the elastic properties of ceramic titanium diboride. J Mater Sci 2001;36:3989-96. DOI

130. Chen D, Xia C, Chen Z, et al. Thermodynamic, elastic and electronic properties of $\mathrm{AlSc}_{2} \mathrm{Si}_{2}$. Mater Lett 2015;138:148-50. DOI

131. Pang M, Zhan Y, Wang H, Jiang W, Du Y. Structural, electronic, elastic and thermodynamic properties of AlSi2RE (RE $=\mathrm{La}, \mathrm{Ce}, \mathrm{Pr}$ and Nd) from first-principle calculations. Comput Mater Sci 2011;50:3303-10. DOI

132. Tang K, Du Q, Li Y. Modelling microstructure evolution during casting, homogenization and ageing heat treatment of Al-Mg-Si-CuFe-Mn alloys. Calphad 2018;63:164-84. DOI

133. Assadiki A, Esin VA, Martinez R, Poole WJ, Cailletaud G. Modelling precipitation hardening in an A356+0.5 wt $\%$ Cu cast aluminum alloy. Mater Sci Eng A 2021;819:141450. DOI

134. Hu Y, Xie J, Liu Z, et al. CA method with machine learning for simulating the grain and pore growth of aluminum alloys. Comput Mater Sci 2018;142:244-54. DOI

135. Li J, Zhang Y, Cao X, et al. Accelerated discovery of high-strength aluminum alloys by machine learning. Commun Mater 2020;1:73. DOI

136. Singh AK, Singhal D, Kumar R. Machining of aluminum 7075 alloy using EDM process: An ANN validation. Mater Today Proc 2020;26:2839-44. DOI

137. Chaudry U, Hamad K, Abuhmed T. Machine learning-aided design of aluminum alloys with high performance. Mater Today Commun 2021;26:101897. DOI

138. Ramprasad R, Batra R, Pilania G, Mannodi-kanakkithodi A, Kim C. Machine learning in materials informatics: recent applications and prospects. npj Comput Mater 2017;3:54. DOI

139. Toyao T, Maeno Z, Takakusagi S, Kamachi T, Takigawa I, Shimizu K. Machine learning for catalysis informatics: recent applications and prospects. ACS Catal 2020;10:2260-97. DOI

140. Peurifoy J, Shen Y, Jing L, et al. Nanophotonic particle simulation and inverse design using artificial neural networks. Sci Adv 2018;4:eaar4206. DOI PubMed PMC

141. Zhang Y, Ling C. A strategy to apply machine learning to small datasets in materials science. npj Comput Mater 2018;4:25. DOI

142. Schleder GR, Padilha ACM, Acosta CM, Costa M, Fazzio A. From DFT to machine learning: recent approaches to materials science-a review. J Phys Mater 2019;2:032001. DOI

143. Feng S, Fu H, Zhou H, Wu Y, Lu Z, Dong H. A general and transferable deep learning framework for predicting phase formation in materials. npj Comput Mater 2021;7:10. DOI

144. LeCun Y, Bengio Y, Hinton G. Deep learning. Nature 2015;521:436-44. DOI PubMed

145. Schmidhuber J. Deep learning in neural networks: an overview. Neural Netw 2015;61:85-117. DOI PubMed

146. Challapalli A, Patel D, Li G. Inverse machine learning framework for optimizing lightweight metamaterials. Mater Des 2021;208:109937. DOI

147. Xiong J, Zhang T, Shi S. Machine learning prediction of elastic properties and glass-forming ability of bulk metallic glasses. MRS Communications 2019;9:576-85. DOI

148. Yao Y, Liu Z, Xie P, et al. Computationally aided, entropy-driven synthesis of highly efficient and durable multi-elemental alloy catalysts. Sci Adv 2020;6:eaaz0510. DOI PubMed PMC

149. Zeng Y, Man M, Bai K, Zhang Y. Revealing high-fidelity phase selection rules for high entropy alloys: a combined CALPHAD and machine learning study. Mater Des 2021;202:109532. DOI

150. Pan S, Wang Y, Yu J, et al. Accelerated discovery of high-performance Cu-Ni-Co-Si alloys through machine learning. Mater Des 2021;209:109929. DOI

151. Jordan MI, Mitchell TM. Machine learning: trends, perspectives, and prospects. Science 2015;349:255-60. DOI PubMed

152. Kalinin SV, Sumpter BG, Archibald RK. Big-deep-smart data in imaging for guiding materials design. Nat Mater 2015;14:973-80.

153. Andolina CM, Wright JG, Das N, Saidi WA. Improved Al-Mg alloy surface segregation predictions with a machine learning atomistic potential. Phys Rev Materials 2021;5:083804. DOI

154. Marchand D, Jain A, Glensk A, Curtin WA. Machine learning for metallurgy I. A neural-network potential for Al-Cu. Phys Rev Materials 2020;4:103601. DOI

155. Jain ACP, Marchand D, Glensk A, Ceriotti M, Curtin WA. Machine learning for metallurgy III: a neural network potential for AlMg-Si. Phys Rev Materials 2021;5:053805. DOI

156. Wang WY, Darling KA, Wang Y, et al. Power law scaled hardness of Mn strengthened nanocrystalline Al Mn non-equilibrium solid solutions. Scr Mater 2016;120:31-6. DOI

157. Zou C, Li J, Wang WY, et al. Revealing the local lattice strains and strengthening mechanisms of Ti alloys. Comput Mater Sci 2018;152:169-77. DOI

158. Wang W, Li J, Liu W, Liu Z. Integrated computational materials engineering for advanced materials: a brief review. Comput Mater Sci 2019;158:42-8. DOI

159. Wang WY, Tang B, Lin D, et al. A brief review of data-driven ICME for intelligently discovering advanced structural metal materials: Insight into atomic and electronic building blocks. J Mater Res 2020;35:872-89. DOI 
160. Zou C, Li J, Wang WY, et al. Integrating data mining and machine learning to discover high-strength ductile titanium alloys. Acta Mater 2021;202:211-21. DOI

161. Jiang L, Wang C, Fu H, Shen J, Zhang Z, Xie J. Discovery of aluminum alloys with ultra-strength and high-toughness via a propertyoriented design strategy. J Mater Sci Technol 2022;98:33-43. DOI

162. Lu Z, Zhang L, Wang J, Yao Q, Rao G, Zhou H. Understanding of strengthening and toughening mechanisms for Sc-modified Al-Si(Mg) series casting alloys designed by computational thermodynamics. J Alloys Compd 2019;805:415-25. DOI

163. Thermo Calc Software. Available from: http://www.thermocalc.com [Last accessed on 28 Dec 2021].

164. Pandat Software. Available from: https://computherm.com [Last accessed on 28 Dec 2021].

165. FactSage Software. Available from: https://www.factsage.com [Last accessed on 28 Dec 2021].

166. MTDTA Software. Available from: https://www.matcalc-engineering.com [Last accessed on 28 Dec 2021].

167. Lu Q, Li K, Chen H, et al. Simultaneously enhanced strength and ductility of 6xxx Al alloys via manipulating meso-scale and nanoscale structures guided with phase equilibrium. J Mater Sci Technol 2020;41:139-48. DOI

168. Yi W, Liu G, Lu Z, Gao J, Zhang L. Efficient alloy design of Sr-modified A356 alloys driven by computational thermodynamics and machine learning. J Mater Sci Technol 2021. DOI

169. Ansara I, Dinsdale AT, Rand MH. Cost 507 definition of thermochemical and thermophysical properties to provide a database for the development of new light alloys: Thermochemical database for light metal alloys. Available from: http://www.opencalphad.com/databases/CGNA18499ENC_001.pdf [Last accessed on 30 Dec 2021].

170. ThermoTech Al-based Alloys Database. Available from: http://www.thermocalc.com/media [Last accessed on 28 Dec 2021].

171. FTlite Database. Available from: https://www.crct.polymtl.ca/fact/documentation [Last accessed on 28 Dec 2021].

172. ME-Al Database. Available from: https://www.matcalc-engineering.com/index.php/databases [Last accessed on 28 Dec 2021].

173. TCAL Database. Available from: https://thermocalc.com/products/databases [Last accessed on 28 Dec 2021].

174. PanAl Database. Available from: https://computherm.com/databases [Last accessed on 28 Dec 2021].

175. Priya P, Johnson DR, Krane MJ. Modeling phase transformation kinetics during homogenization of aluminum alloy 7050. Comput Mater Sci 2017;138:277-87. DOI

176. Ahn T, Jung J, Baek E, Hwang SS, Euh K. Temporal evolution of precipitates in multicomponent Al-6Mg-9Si-10Cu-10Zn-3Ni alloy studied by complementary experimental methods. J Alloys Compd 2017;701:660-8. DOI

177. Brollo GL, de Paula LC, Proni CTW, Zoqui EJ. Analysis of the thermodynamic behavior of A355 and B319 alloys using the differentiation method. Thermochim Acta 2018;659:121-35. DOI

178. Chen SL, Zhang F, Xie FY, et al. Calculating phase diagrams using PANDAT and panengine. JOM 2003;55:48-51. DOI

179. Chen S, Daniel S, Zhang F, et al. The PANDAT software package and its applications. Calphad 2002;26:175-88. DOI

180. Bocklund B, Otis R, Egorov A, Obaied A, Roslyakova I, Liu Z. ESPEI for efficient thermodynamic database development, modification, and uncertainty quantification: application to Cu-Mg. MRS Commun 2019;9:618-27. DOI

181. Cai Q, Mendis CL, Chang IT, Fan Z. Microstructure and mechanical properties of new die-cast quaternary Al-Cu-Si-Mg alloys. Mater Sci Eng A 2021;800:140357. DOI

182. Chen H, Chen Q, Bratberg J, Engström A. Predictions of stable and metastable phase formations in aluminum alloys. Mater Today Proc 2015;2:4939-48. DOI

183. Myhr O. Modelling of the age hardening behaviour of Al-Mg-Si alloys. Acta Mater 2001;49:65-75. DOI

184. Yi W, Gao J, Tang Y, Zhang L. Thermodynamic descriptions of ternary Al-Si-Sr system supported by key experiments. Calphad 2020;68:101732. DOI

185. Gao J, Zhong J, Liu G, et al. A machine learning accelerated distributed task management system (Malac-Distmas) and its application in high-throughput CALPHAD computations aiming at efficient alloy design. Adv Powder Mater 2021. DOI

186. Zhang J, Gao J, Song B, et al. A novel crack-free Ti-modified Al-Cu-Mg alloy designed for selective laser melting. Addit Manuf 2021;38:101829. DOI 